
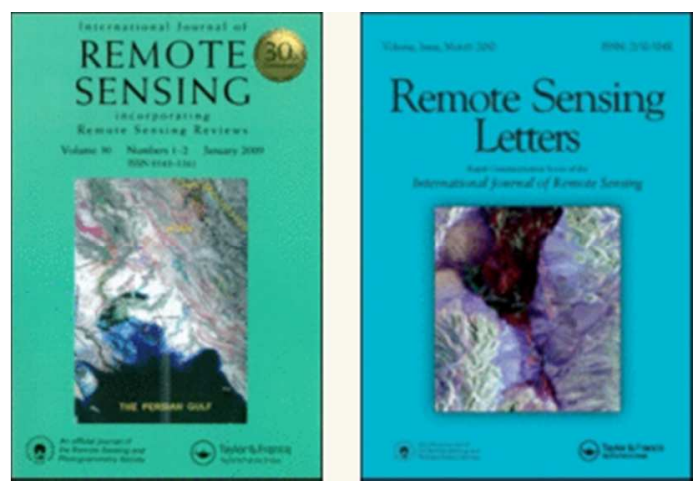

\title{
Assessing Woody Biomass in African Tropical Savannahs by Multiscale Remote Sensing
}

\begin{tabular}{|r|l|}
\hline Journal: & International Journal of Remote Sensing \\
\hline Manuscript ID: & TRES-PAP-2011-0695.R3 \\
\hline Manuscript Type: & IJRS Research Paper \\
\hline Date Submitted by the Author: & n/a \\
\hline Keywote List of Authors: & $\begin{array}{l}\text { Wu, Weicheng; ICARDA (International Center for Agricultural Research in } \\
\text { Dry Areas), GISU } \\
\text { De Pauw, Eddy; ICARDA (International Center for Agricultural Research in } \\
\text { Dry Areas), GISU } \\
\text { Hellden, Ulf; Lund University, Department of Earth and Ecosystem Sciences }\end{array}$ \\
\hline Keywords (user defined): & $\begin{array}{l}\text { BIOMASS, IMAGE PROCESSING, VEGETATION INDEX, OPTICAL REMOTE } \\
\text { MENSING }\end{array}$ \\
\hline &
\end{tabular}




\title{
Assessing woody biomass in African tropical savannahs by multiscale remote sensing
}

\author{
WEICHENG WU $+\stackrel{+}{\dagger}$, EDDY DE PAUW $\dagger$ and ULF HELLDÉN + \\ $\uparrow$ GISU/ICARDA (International Center for Agricultural Research in the Dry Areas), POBox 950764, \\ Amman, Jordan \\ ‡Department of Earth and Ecosystem Sciences, Lund University, Solvegatan 12, S-223 62 Lund, Sweden
}

\begin{abstract}
Woody biomass production is a critical indicator to evaluate land use management and the dynamics of the global carbon cycle (sequestration/emission) in terrestrial ecosystems. The objective of the present study was to develop through a case study in Sudan an operational multiscale remote sensing-based methodology for large-scale estimation of woody biomass in tropical savannahs. Woody biomass estimation models obtained by different authors from destructive field measurements in different tropical savannah ecosystems were expressed as functions of tree canopy cover (CC). The field-measured CC data were used for developing regression equations with atmospherically corrected and reflectance-based vegetation indices derived from Landsat ETM+ (Enhanced Thematic Mapper) imagery. Among a set of vegetation indices, the Normalized Difference Vegetation Index (NDVI) provided the best correlation with CC $\left(\mathrm{R}^{2}=0.91\right)$ and was hence selected for woodland woody biomass estimation. After validation of the CC-NDVI model and its applicability to MODIS (Moderate Resolution Imaging Spectroradiometer) data, time series MODIS NDVI data (MOD13Q1) were used to partition the woody component from the herbaceous component for sparse woodlands, woodlands and forests defined by FAO Land Cover Map. Following the weighting of the estimation models based on the dominant woody species in each vegetation community ${ }_{2}$ NDVI-based woody biomass models were applied according to their weighted ratios to the decomposed summer and autumn woody NDVI images in all vegetation communities in the whole of Sudan taking the year 2007 for example. The results were found to be in good agreement with the results from other authors obtained by field measurements or by other remote sensing methods using MODIS and Lidar data. It is concluded that the proposed approach is operational and can be applied for a reliable large-scale assessment of woody biomass at a ground

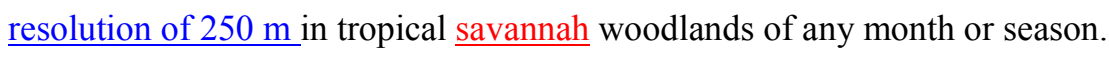

\section{Introduction}

${ }^{1}$ Corresponding author. E-mail address: w.wu@,cgiar.org 
Woody biomass is a measure of cumulative above_ground net primary production (NPP) of trees or shrubs in a certain period of time and is expressed as weight of dry matter per unit area, e.g. tons ha- ${ }^{-1}$. Information about woody biomass is critical because it is closely related to land use practice and management in savannahs and forest ecosystems, for example, deforestation, slash-and-burn agriculture activities. The Intergovernmental Panel on Climate Change (IPCC) reported that 68.6$75.9 \%$ of the total annual NPP are concentrated in the biomes of boreal and temperate forests, tropical rainforests, and particularly in tropical savannah woodlands, in which the last ones account for 23.8-29.5\% of contribution to the total annual NPP (IPCC 2001). Therefore, tropical savannah woodlands constitute an essential part of the global terrestrial ecosystem and play an important role in agroforestry and socio-economic development in tropical regions, not only for their energy, food, wood, and wood-based industry, but also for their critical multi-function part in controlling the equilibrium between carbon emission and sequestration, climate change, and in preserving the soil against desertification and land degradation (Hall et al. 1985, Dixon et al. 1994, Campbell 1996, Frost 1996, Foley et al. 2005, UNEP 2006). Monitoring and assessment of the woody biomass production of the savannah ecosystems at the regional scale is hence of major importance for the assessment of the state of the globe, particularly- in the context of climate change and land degradation, and for making sustainable land management decisions in related countries and regions.

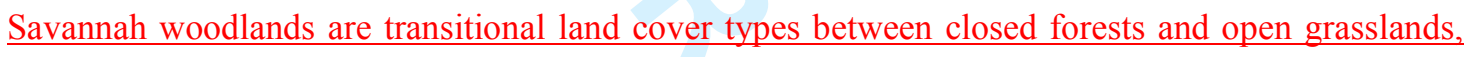
with tree canopy cover (CC) less dense than forests, but more than grasslands. Savannah biomes are very common in tropical Africa, where they occupy a large region that is conventionally subdivided into Southern Saharan/Sahelian Woodlands, Sudanian Woodlands in the north of the equator, and Miombo Woodlands in the south. Given the continuum in CC within this large ecosystem, different subdivisions have been proposed for savannah woodlands based on CC (White 1983, Helldén 1987b, FAO 2000). Since we intend to use the land cover map produced by FAO Africover Project (FAO 2003) to largely identify the woodland and forest areas, we follow the division of the FAO Land Cover Classification System (Di Gregorio and Jansen 2000); and in this paper we use the following class terms: sparse woodland including wooded grassland and open woodland (tree/shrub CC: 120\%), woodland/shrubland (CC: $20-60 \%$ ), and forest (CC: $>60 \%$ ). However, this classification cannot fully reveal the variability and mixture of the woody species in tropical savannah woodlands in space. For this reason, it is better to also take into account information on vegetation communities (Harrison and Jackson 1958) in order to understand not only the diversity of woody species crossing different savannahs, but also their dominance in each community in each savannah eco-region (table 1) in tropical Africa.

The extensive assessment of woody biomass is based on models that extrapolate actual measures of tree biomass, obtained in sampling sites, to large areas by establishing statistical relationships with indirect indicators of vegetation biomass, usually obtained by remote sensing. For boreal and tropical forests, a significant number of woody biomass assessments have been undertaken either 
using allometric equations (e.g. Baskerville 1972, Brown et al. 1989, Iverson et al. 1994, Brown and Gaston 1995, FAO 1997, Sawadogo et al. 2010) or optical and radar remote sensing (Debson et al. 1992, Foody et al. 2003, Popescu et al. 2003, Zheng et al. 2004, Lu et al. 2005, Rauste 2005, Heiskanen 2006, and Baccini et al. 2008). Given differences between biomes in species, CC, and environmental conditions, woody biomass models developed for specific biomes for boreal forests and tropical rainforests are not applicable in savannah woodlands.

For the tropical savannah woodlands, some studies have attempted to establish CC-based woody biomass (WB) models. Helldén and Olsson (1982), Olsson (1985), and Helldén (1987a, 1987b and 1991) have conducted biomass assessment in Acacia-dominated Saharan/Sahelian woodlands in

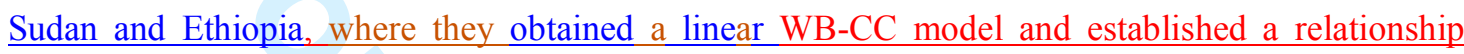
between CC and NDVI (Rouse et al. 1973, Tucker 1979). Their studies confirmed the feasibility to assess woody biomass by remote sensing. While investigating carbon stocks in the Sahelian $\underline{\text { Savannah in Senegal, Woomer et al. (2004) also reported a linear model between total carbon and }}$ CC. Due to some shortcomings these models cannot be directly applied to larger regions of interest. In the CC-NDVI model of Helldén, the NDVI was derived from Landsat MSS (Multispectral Scanner System) and TM (Thematic Mapper) images without atmospheric correction, and the radiance values were not converted into reflectance. The model of Woomer et al. (2004) was focused only on sparse woodlands $(\mathrm{CC}<28 \%)$ and is therefore not applicable to Sudanian woodlands.

Orthmann (2005) measured WB and CC in field in Benin allowing us to establish a power WB-CC model for Sudanian Savannah. Some authors (Malimbwi et al. 1994, Campbell 1996, Frost 1996) studied WB in Miombo Woodlands but did not report any relevant model coupling WB and CC. Suganuma et al. (2006) built up WB-CC models in Western Australian Savannah but their models cannot be directly applied in tropical Africa due to the endemic difference in woody species and environment.

From the above brief review, it is clear that due to their particular limitations, no regional-scale woody biomass assessment can be undertaken in tropical Africa based on a single WB-CC model, because none of them are spatially representative enough to cover all savannah biomes and diversity of vegetation communities.

The main objective of this study was therefore to develop a regionally valid and year-round operational woody biomass assessment methodology for the African tropical savannah ecosystems north of the equator by remote sensing based on existing studies. Sudan, the largest African country ${ }^{2}$, encompassing a very representative cross-section of tropical savannah woodlands including the Southern Saharan, Sahelian, and Sudanian Savannahs (WWF 2010, figure 1), was selected as a basis for developing and testing the methodology.

I In this paper, we are talking about the Sudan before 9 July 2011, when South Sudan became independent. 
Table 1. Woody vegetation diversity and communities in tropical savannahs taking Sudan for example

\section{Figure 1. Distribution of CC sampling plots and coverage of Landsat scenes}

Note: (1). The division of eco-regions or different savannahs was based on the annual rainfall of the period 1980-1999 according to WWF (2010); (2) Light blue and red image frames indicate respectively the 16 Landsat ETM+ scenes used for CC-VI model development and 11 scenes for CC-VI model evaluation in this study; (3) two sets of sampling plots: one includes 177 plots (in light blue) for development of CC-VI models and the other contains 72 plots (in red) for CC-VI model evaluation

\section{Methods}

Based on the understanding of the background of the study area (subsection 2.1), large-scale woody biomass assessment in tropical savannahs requires a multi-scale remote sensing approach which includes five major steps: calibration of the relevant WB-CC models for different savannah woodlands (subsection 2.2); development of generally valid CC-VI (vegetation index) models by coupling field-measured $\mathrm{CC}$ with remote sensing VIs derived from high resolution imagery (subsection 2.3); region- or country-scale biomass modelling using relevant WB-VI models based on extraction of the woody component by time-series analysis (subsection 2.4); model weighting and application to vegetation community for biomass estimation (subsection 2.5); and lastly, biomass map evaluation (subsection 2.6). For this purpose, a multi-resolution satellite dataset, composed of very-high-resolution satellite images, such as QuickBird (partly GeoEye) images (0.5-2.5 m) that are available in Google Earth, 27 Landsat ETM+ images $(15-30 \mathrm{~m})$ which are sensitive to local scale phenological change in land cover, and time-series moderate resolution data namely MOD13Q1 and MOD09Q1 $(250 \mathrm{~m})$ products, were prepared (table 2) and the global procedure is demonstrated in the flowchart (figure 2).

Table 2. Satellite dataset used in this study

Figure 2. Flow chart of the methodology and procedure adopted in this study (Note: it is the subsection number in parenthesis)

\subsection{The study area}


A typical tropical savannah country and located in East Africa, Sudan covers a territory of 2.51 million $\mathrm{km}^{2}$, where the average temperature does not vary greatly throughout the year (e.g. from 25 to $35^{\circ} \mathrm{C}$ in Khartoum) but the annual rainfall has a strong variation in space from north $(0 \mathrm{~mm}$ in

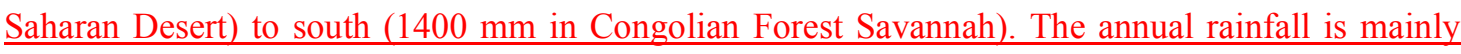
concentrated between June and September (88-93\% of the total rainfall) in Saharan and Sahelian Savannahs (dry season starts from October), and between May and October (82-91\% of the total rainfall) in Sudanian and Congolian Savannahs, where the dry season starts from November.

According to the FAO Africover Land Cover Map (FAO 2003), there are 23 main land use and cover types which can be further integrated into the following major classes: bare soil (mainly Saharan Desert, 36.33\%), grasslands (in Saharan and Sahelian eco-regions, 8.19\%), croplands $(5.83 \%)$, sparse woodlands (including sparse shrublands and wooded grasslands, 16.88\%), woodlands (including shrublands, $31.59 \%$ ), forests $(0.29 \%$ ), water bodies (lakes and rivers, $0.56 \%$ ), swamp (0.22\%), and artificial (urban areas, villages and road infrastructures, $0.11 \%$ ). Therefore woodlands (including sparse woodlands) crossing different savannah belts are the most important land cover in Sudan (48.47\%). About 1.2 million $\mathrm{km}^{2}$ of woodlands crossing Saharan, Sahelian, Sudanian and Congolian Savannahs are included in our study.

\subsection{Calibration of WB-CC models}

To assess woody biomass in the tropical savannahs, the first need is to calibrate reliable WB-CC models, which are usually obtained from field measurement. Whereas in-situ measurements of the woody biomass and canopy cover in different savannah ecosystems were planned in the beginning of the study, we were not recommended to go due to security reasons and we had to use the models developed by other authors, if relevant and applicable to our study.

As mentioned earlier, Helldén and others conducted field measurements for the species Acacia albida, Acacia mellifera, Acacia senegal, Acacia seyal, Acacia tortilis, Albizzia amara, Balanites aegyptiaca in the Saharan/Sahelian Savannahs in 1980s. Helldén (1991) incorporated all the field measurements in Kassala, Gedaref, and North Kordofan in Sudan, Gojam and Shewa in Ethiopia to develop the Acacia-dominated WB-CC model (equation (1)) and to obtain the relationship between CC and NDVI (equation (2)), which can be respectively expressed as follows:

$$
\begin{aligned}
& \underline{B}_{\underline{W}}=0.4644 C C-0.6286\left(\mathrm{R}^{2}=0.96\right) \\
& C C=-366+6.01 N D V I_{\underline{d c}}\left(\mathrm{R}^{2}=0.90\right)
\end{aligned}
$$

$\underline{\text { where } B_{W}}$ - dry weight woody biomass $\left(\right.$ tons $\left.\mathrm{ha}^{-1}\right), C C$ in percentage (\%) and $N D V I_{d c}=$ NDVI Digital Counts.

Despite the limitation of equation (2), as recognised earlier, the CC measurement in their studies covers a range of $3-47 \%$, which is much wider than that of Woomer et al. (2004). Franklin and Hiernaux (1991), in their assessment in western Sahelian/Sudanian Savannahs in Mali, confirmed 
that the model of Helldén (1987a and 1987b) produced better results than those of Olsson (1985) and Bille (1977). Thus, for the Acacia-dominated Sahelian/Saharan Woodlands, the model of Helldén, equation (1), was considered representative.

For the Sudanian Woodlands, equation (1) is clearly not relevant due to the differences with the Sahelian Woodlands in dominant woody species and environmental conditions. Fortunately, Orthmann (2005) measured woody biomass of 51 species in 35 plots $(30 \mathrm{~m} \times 30 \mathrm{~m})$ in the Western Sudanian Savannah in Benin, which floristically resemble those in the Eastern Sudanian Savannah eco-region, where Anogeissus-Isoberlinia-Uapaca-Terminalia is the dominant combination. From her measured data, the following power WB-CC relationship, taking all measured trees into account, was obtained:

$$
\underline{B}_{\underline{W}}=0.8868 C C^{1.1069}\left(\mathrm{R}^{2}=0.95\right)
$$

This WB-CC model was regarded as representative for the Sudanian Woodlands as it covers most dominant woody species -in the Sudanian eco-region.

The two models, in spite of their representativeness for individual biomes, do not cover all woody species in all woodlands savannahs. As evidenced by table 1, the dominant species show much variation in space and often occur in different savannah biomes. For example, some dominant species in Saharan/Sahelian Savannahs (e.g. Acacia seyal, Balanites) also occur in the Sudanian ecoregion, and vice versa. To avoid over- or underestimation, a combination usage of the two models based on the dominance of woody vegetation in each community seems essential. More detail will be provided in Subsection 2.5.

\subsection{Development of $\mathrm{CC}$ - $\underline{\text { VI models }}$}

To develop CC-VI models, it is necessary to derive the most relevant VIs from high resolution satellite images, in our case from Landsat ETM+ images (2.3.1), then measure CC in the field or in very high resolution images/air photos of different savannah woodlands (2.3.2), followed by a calibration of CC-VI models by regression analysis (2.3.3), and finally, to evaluate the applicability of the developed CC-VI model in different savannahs (2.3.4).

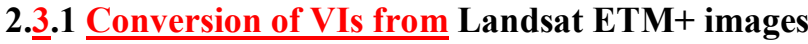

Phenologically, herbaceous vegetation in tropical savannahs is affected by senescing but Acacia, coniferous, and broadleaved deciduous trees are still green in November, whereas in the dry months from December to February not only frequent woodland fires occur but also the deciduous species lose leaves. For this reason, November images are most pertinent for CC-VI calibration study as the contrast between woody and herbaceous vegetation is maximized.

Sixteen November Landsat ETM+ images acquired in the period 1999-2002, the only available satellite imagery source we could find at no charge before February 2009, were obtained (see figure 
$\underline{1 \text { and table } 2 \text { for spatial coverage) and employed for CC-VI modelling. After February 2009, all }}$ Landsat data became publicly available at no charge as a decision of USGS (United States Geological Survey). Thus we got another set of 11 scenes November Landsat ETM+ images of the same period 1999-2002 (see figure 1 and table 2). These 11 images were not used for CC-VI model development but for CC-VI model evaluation. The image processing of all Landsat imagery includes: Atmospheric correction: The obtained Landsat images were radiometrically normalized and atmospherically corrected using the COST model developed by Chavez (1996), which intends to remove both additive scattering and multiplicative path transmission effects. The haze values of images in Digital Number (DN) shown in table $\underline{2}$, an important input for the COST model, were estimated using the $4^{\text {th }}$ feature of the Tasseled Cap Transformation (Crist et al. 1984a and 1984b). The haze removal was conducted in terms of the multiplication factor for each band proposed by Chavez (1988). The correction procedure is described by $\mathrm{Wu}$ (2003).

Transformation of multispectral reflectance into relevant $\underline{\text { VIs: }}$ In addition to NDVI, we considered that other VIs might be also useful for biomass estimation in terms of their development theories, such as the Enhanced Vegetation Index (EVI 2 Huete et al. 1997) and the Soil Adjusted and Atmospherically Resistant Vegetation Index (SARVI) proposed by Kaufman and Tanré (1992). These vegetation indices introduce the blue band to conduct a self-correction and remove not only soil influence but also atmospheric effects. Also the Visible Atmospherically Resistant Index (VARI) and the Wide Dynamic Range Vegetation Index (WDRVI) developed by Gitelson et al. (2002) and Gitelson (2004) were considered in view of their reported higher sensitivity than NDVI to vegetation with a moderate-to-high Leaf Area Index $(\mathrm{LAI}=2-6)$. For calibration of the CC-VI models, the reflectance-based NDVI, EVI, SARVI, VARI and WDRVI were produced. However, in any ETM+ image VARI and WDRVI values are negative in most pixels, except for some tracts of cropland. For this reason, only NDVI, SARVI and EVI were selected for further calibration.

\section{3. $\underline{\text { C }}$ C measurement}

$\underline{\mathrm{CC} \text { measurement is the key for developing CC-VI models and its evaluation. It requires a rational }}$ and representative selection of plots for sampling. Based on FAO Land Cover Map, the ratio of the surface areas among sparse woodlands, woodlands and forests was obtained, that is, 58:109:1. In consideration of the available time investment and the requirement that sampling has to be spatially representative, we decided to assign randomly 500 points in total to these woodlands where there was coverage of QuickBird imagery as per the ratio so that 172 points were distributed in sparse woodlands, 324 in woodlands and 3 in forests. By removing those located in the cloud-covered and burnt areas in QuickBird images (where replacement was not possible due to absence of trees or shrubs in the adjacent areas), 287 points were left; then using 16 Landsat frames to clip, 177 points (of which 6 are located in Southern Saharan, 86 in Sahelian, 75 in Sudanian, and 10 in Congolian eco-regions and were considered spatially representative) were finally retained for CC sampling. The 
plot selection was hence half stratified half random or stratified random covering all savannah woodlands within the coverage of available QuickBird imagery and Landsat frames.

Using Google Earth, we conducted CC sampling plot by plot at the location of each of the above points. The plot, taking one of the above points as centre, covers an area of $100 \mathrm{~m} \times 100 \mathrm{~m}(1 \mathrm{ha})$. The plot size is in fact a compromise between the resolutions of Landsat $(30 \mathrm{~m})$ and MODIS $(250 \mathrm{~m})$ data viewing that the $\mathrm{CC}$ sampling results would be applied to both two satellite imagery. In each plot $_{2}$ we counted the number of trees, measured canopy diameter, and calculated CC as follows:

$$
C C=\frac{\pi}{4} \sum_{i=1}^{n} d_{i}^{2}
$$

where $n$ is the number of trees in the 1-ha plot, and $d_{i}$ is the canopy diameter of tree $i$. Trees or shrubs with canopy diameter $\left(d_{i}\right)<2$ m were not counted because firstly, it is difficult to measure as a result of resolution degradation of QuickBird (including very locally GeoEye) images in Google Earth (their resolution is not $0.6-1.0 \mathrm{~m}$ but about $1.5-2.0 \mathrm{~m}$ in rural areas); and secondly, their biomass is negligible (about 1.6-3.0\% of the total woody biomass) according to the measurement by Orthmann (2005) in tree savannah and savannah woodland. Counting manually all trees and measuring their crown diameters are tedious and very time consuming, especially when the number of trees exceeds 40-50. In its favour, the method is simple and easy to apply, especially in case of crown shading due to a low sun-elevation angle and low heterogeneity among tree canopy sizes.

Another approach to measure CC consisted in copying the 1-ha plot sampling area from Google Earth using the Print-Screen function of the keyboard and paste it into Photoshop. After discarding the colour information, the plot was turned into a black-and-white image. By enhancing the contrast between the crown area (dark) and background soil (white), the number of black pixels can be easily read to get the crown area percentage ${ }^{1}$. The main limitation of this method is that it can be only applied in the plots where there is an apparent difference in reflectance between canopy cover and background soil, and when the sun-elevation angle is large enough not to produce much crown shadow.

Both methods were compared for accuracy and reliability in five plots (four in Sahelian and one in Sudanian) where QuickBird images were acquired in later spring and summer and both approaches were applied for $\mathrm{CC}$ sampling. It was noted that the difference between the two approaches varied between 3 and 7\%; and if the images are obtained in summer without much canopy shadow, the second approach is more accurate and more time-effective.

\section{$\underline{\text { 2.3.3 CC-VI models }}$}

\footnotetext{
| 1 Method developed based on a personal communication with Dr Rolf Sommer_(ICARDA), October, 2008.
} 
While plotting the $\mathrm{CC}$ of these 177 sampling plots against the $\underline{16}$ November Landsat ETM+ images, the correlation between the $\mathrm{CC}$ and the vegetation indices, which are the weighted values of nine pixels within a kernel size of $3 \times 3$ (more or less equivalent to the plot size, 1 ha), was very low $\left(\mathrm{R}^{2}=\right.$ 0.16). Our first concern was that whether the low correlation was a consequence of the difference in

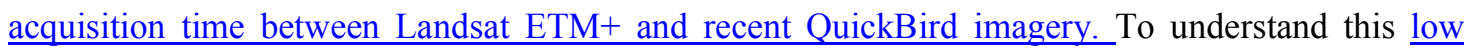
correlation phenomenon and explore the applicability of the Landsat ETM+ imagery for this CC-VIs calibration, for each of the 177 plots the QuickBird was compared with the corresponding Landsat ETM+ image. Major discrepancies occurred in the following cases: (a) forest/woodland fire in November ETM+ images (1999-2002), but regrowth of trees or shrubs in the recent QuickBird images (low VIs vs. high CC case); (b) recent woodland fire: burning occurred 1-2 years before image acquisition but burnt scars still clearly distinguishable in the QuickBird images, with high VIs in the ETM+ images (high VIs vs. low CC case; measured CC cannot represent that when Landsat images were acquired); and (c) a very green herbaceous understory (high VIs) in the November $\mathrm{ETM}+$ images but with low tree density (low CC) measured in the QuickBird images, particularly in the Sudanian Savannahs (again high VIs vs. low CC). The plots belonging to these three abnormal cases were excluded. The defect related to the occurrence of the sudden events during the period of difference was thus reduced. Whether the retained plots, in total 82 (of which 6 are distributed in Saharan, 62 in Sahelian and 14 in Sudanian savannahs), are pertinent for calibration, we need a further check on the tree/shrub canopy growth rate in its natural state without disturbance (e.g. fire). If the growth rate is high, old images cannot represent the $\mathrm{CC}$ of 3-8 years after. For this reason, we carefully selected some previous and new plots, in which QuickBird image pairs acquired in the same month but in different years could be found in Google Earth, to investigate the annual canopy growth rate. It is noted that the average annual growth rate of the observed five sites (perhaps still not representative enough in space) is about $1.55 \%$. For a period of $3-8$ years, the difference from the measured CC may be around 4.7-12.4\%; and such a difference should fall in the scope of the tolerable error in satellite remote sensing field, especially, when we are dealing with moderate resolution data. We considered hence the November Land ETM+ data can still be used for CC-VIs calibration despite of the difference in time acquisition.

The measured $\mathrm{CC}$ of the retained 82 plots, were projected against the VIs using least-square linear regression models, and we obtained a clear and strong correlation between $\mathrm{CC}$ and VIs $\left(\mathrm{R}^{2}=0.83\right.$

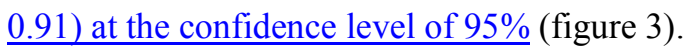

Although there were some concerns on the use of NDVI to infer vegetation and soil properties, especially in drylands (Huete 1988, Kaufman and Tanré 1992, Huete et al. 1997, Gitelson 2004), the calibration revealed that among the three vegetation indices the atmospherically corrected reflectance-based NDVI showed the best correlation with $\mathrm{CC}\left(\mathrm{R}^{2}=0.91\right.$, figure 3a). SARVI has the same level of correlation with $\mathrm{CC}\left(\mathrm{R}^{2}=0.90\right)$ as NDVI but with a lower dynamic range $(0.1-0.2$ units lower than that of NDVI and EVI). For this reason, we selected NDVI as CC indicator for 
biomass estimation. Since we have excluded the herbaceous influence, here the NDVI is woody NDVI. We can denote it as $N D V I_{W}$. The equation between CC and NDVI can be expressed as:

$$
C C=153.09 N D V I_{W}-10.12 \quad\left(\mathrm{R}^{2}=0.91\right)
$$

\subsubsection{Evaluation of CC-NDVI model}

To test the applicability and validity of the CC-NDVI model crossing different savannahs, we used the other set of 11 scenes of Landsat ETM+ images (table 2), which were obtained after February 2009, to derive, or rather, to predict CC in the sparse woodland, woodland and forest areas using equation (5). Again, we used these 11 Landsat frames to intercept the same 500 points created in 2.3.2. By removing those in cloud covered areas, bare land and burnt scars in both QuickBird and Landsat ETM+ images, 72 points (18 in Saharan, 37 in Sahelian, and 17 in Sudanian Savannahs) were retained for sampling. So a new set of- $\mathrm{CC}$ samples were measured again in Google Earth (see figure 1: Plots for validation). By coupling the predicted weighted CC from nine pixels derived from the 11 Landsat images using equation (5) vs. the measured CC using linear least-square regression model at confidence level of $95 \%$, we obtained a very high $\mathrm{R}^{2}$ value $(0.95)$. If we remove the four outliers (two overestimated and one underestimated cases in the rainforests, and the third case in woodland but with green herbaceous vegetation in November image) in the Sudanian Savannah, the

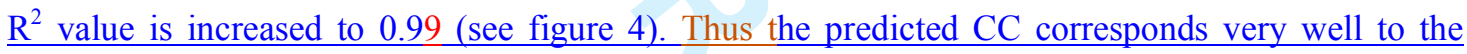
measured $\mathrm{CC}$ and the CC-NDVI model can reliably predict $\mathrm{CC}$ crossing different savannah woodlands.

Figure 3. The relationships between the measured CC and VIs

\section{Figure 4. Agreement between the measured and predicted CC}

\section{$\underline{\text { 2.3.5 Upscaling analysis }}$}

Since the CC-NDVI model was developed based on Landsat ETM+ images, a critical step was to evaluate whether they can be directly applied to MODIS data, because the sensed information between the two captors is not identical, even for the same targets or objects, due to the difference in spatial resolution and nadir viewing angle. For this purpose, three Landsat ETM+ images (176-53 and 176-54 dated 17 November 2002, and 179-51 dated 6 November 2002, table 2) and two frames of MOD13Q1 (250 m) NDVI images (H20V07 and H20V08 of 16 November 2002) were selected for this upscaling test. To have more comparability with MODIS data and diminish the difference in spatial resolution, the three scenes of Landsat NDVI were resampled to $250 \mathrm{~m}$ resolution. To ensure enough check points to cover all land cover types in space, mainly sparse woodlands, woodlands, swamp and croplands in each scene of the three Landsat images, and to have also a quick assessment, 
$\underline{2000}$ points in total were randomly generated, of which 1 _655 points were finally retained for extraction of the NDVI values from both Landsat and MODIS data, after removing those falling in rivers and burnt areas. The NDVI of Landsat ETM+ images $\left(\mathrm{NDVI}_{\mathrm{L}}\right)$ and that of MODIS $\left(\mathrm{NDVI}_{\mathrm{M}}\right)$ of the same time or more or less at the same time period are strongly correlated $\left(\mathrm{NDVI}_{\mathrm{M}}=\right.$ $0.9786 \mathrm{NDVI}_{\mathrm{L}}+0.0471, \mathrm{R}^{2}=0.88$ ).

Another approach to test the applicability is to apply a differencing technique to see their agreement between MODIS and Landsat NDVI images. After subsetting the MODIS NDVI image into the same size as three Landsat NDVI images, the former was subtracted by the latter, followed with a statistical analysis which indicates a normal leptokurtic distribution, where the mean (M) is -0.041 ; the standard deviation $(\sigma)$ is 0.060 ; the minimum (Min) and maximum (Max) are respectively -0.863 and 0.528. It was noted that pixels between $\mathrm{M}-\sigma(-0.101)$ and $\mathrm{M}+\sigma(0.018)$ take up $78.38 \%$, and between $\mathrm{M}-2 \sigma(-0.161)$ and $\mathrm{M}+2 \sigma(0.078) 94.91 \%$. The little percentage of the abnormal pixels distributed in the two tail ends of the histogram were burning or burnt areas $(2.79 \%)$ and herbaceous vegetation senescing $(2.31 \%)$ along the river running courses in the 11 days' observation period from 06 to 17 November 2002. Thus, if we don't consider the abnormal pixels, MODIS and Landsat NDVIs are consistent to each other.

Both approaches confirmed the feasibility to transfer models developed from Landsat ETM+ images to MODIS data and to upscale from local level studies to regional or nationwide assessments.

\subsection{Modelling woody biomass}

For regional woody biomass assessment, it is essential to have representative biomass models corresponding to different savannahs based on the relationship of CC-NDVI (2.4.1) and relevant input such as regional scale woody NDVI (2.4.2).

\subsubsection{W $\underline{B}-$ NDVI models}

As calibrated in subsection 2.2, we have two WB-CC models relevant respectively for $\underline{\text { Saharan/Sahelian and Sudanian Savannahs. Through the CC-VI model development in subsection }}$ 2.3, we have now the CC-NDVI model, equation (5), which is applicable to multiple tropical savannahs. We can combine equations $\underline{\text { (1) and (5) to get WB-NDVI model for Acacia-dominated }}$ $\underline{\text { Saharan/Sahelian Savannahs (Model 1), and merge equations (3) and (5) to get the WB-NDVI model }}$ for Sudanian eco-region (Model 2):

Model 1: $B_{W}=71.095 N D V I_{W}-5.3283$

Model 2: $B_{W}=0.8868\left(153.09 N D V I_{W}-10.12\right)^{1.1069}$

These models allow regional woody biomass assessment by direct application to the most popular $\underline{\text { remote sensing product such as NDVI if the woody component }\left(\mathrm{NDVI}_{\mathrm{W}}\right) \text { can be extracted. }}$ 


\subsubsection{Derivation of woody NDVI by time-series analysis}

As already mentioned earlier in section 1, woodland is the land cover between grassland and forest, and itself is a mixture of trees or shrubs together with annual herbaceous vegetation. In savannahs, tree cover is generally low, especially in lower-rainfall zones, but may locally be dense, particularly in lowlands and valleys dominated by Acacia in the southern Saharan and Sahelian woodlands. With higher rainfall tree cover becomes generally denser, as is the case in the Anogeissus-KhayaIsoberlinia and Combretum-Terminalia-dominated Sudanian Savannahs (Harrison and Jackson 1958, White 1983, Franklin and Hiernaux 1991, Hiernaux and Le Houérou 2006). Hence, the NDVI value of a pixel is not completely contributed by the tree cover but also by the herbaceous vegetation. Normally, using imagery of autumn (e.g. November), the confounding influence of herbaceous vegetation can be minimized, but cannot be completely removed because in lowlands, valleys, and riparian plains, grasses are still green favoured by available moisture, especially, in the Sudanian and Congolian Savannahs.

It is evident that no matter which period of imagery we use, the herbaceous confusion is always a challenge for woody biomass assessment by remote sensing, especially in the Sudanian and Congolian eco-regions. To achieve our objective to develop an approach to estimate year-round woody biomass, it is essential to separate the woody component from the herbaceous one in any image of any season; and time-series analysis provides a useful tool for this purpose.

Research by Roderick et al. (1999), Lu et al. (2003), and Verbesselt et al. (2010) indicates that timeseries NDVI data can be decomposed into a trend, a seasonal change, and a random or irregular change component. Verbesselt et al. (2010) used time-series trend analysis to detect abrupt changes while Roderick et al. (1999) and $\mathrm{Lu}$ et al. (2003) used this technique to partition the woody component from the herbaceous one. In this study we adopted the same concepts as trend and baseline of Roderick et al. (1999) and Lu et al. (2003) and applied these to eight years of MODIS NDVI time-series data (MOD13Q1 product) from January 2002 to December 2009 (96 months and 184 acquisitions for each of the six frames) for decomposition.

Within the FAO Land Cover Map defined sparse woodlands, woodlands and forests, a number of polygons were respectively defined in the MODIS NDVI images crossing Sahelian and Sudanian

Savannahs to have spatial representativeness. The polygons of forests cover 795 pixels; those of woodlands and sparse woodlands take up respectively 4048 pixels and 5006 pixels. The corresponding time-series monthly average NDVI datasets from January 2002 to December 2009 were extracted using these polygons. Then the time-series NDVI dataset of each type of woodlands was decomposed into a trend and seasonal component, following the "locally weighted regression smoother (LOESS)" approach proposed by Cleveland et al. (1990) using R-Code developed by Wessa (2008). The decomposed results are shown in figure $\underline{5}$. According to Roderick et al. (1999) and $\mathrm{Lu}$ et al. (2003), the baseline $\left(N D V I_{B i}\right)$, which can be obtained by shifting the trend of NDVI 
$\left(N D V I_{T i}\right)$ by a constant $K$, is a good measure of the evergreen woody NDVI or woody component $\left(N D V I_{W i}\right)$ at the given time $i$ and can be expressed as:

$$
N D V I_{W i}=N D V I_{B i}=N D V I_{T i}-K
$$

where $K$ is the absolute value of minimum seasonal component for the two consecutive years. $K$ for forest, woodland ${ }_{2}$ and sparse woodland was respectively measured $0.1466,0.2143$ and 0.1982 for the entire period of eight years. The baseline is shown in figure $\underline{5}$. The percentage of the woody component, in other words, the ratio $\underline{(\mathrm{R} \%)}$ between the woody component $\left(N D V I_{W}\right)$ and the observed NDVI $\left(N D V I_{O}\right)$, in our case, the NDVI of MOD13Q1 product, of a given pixel at any time $i$ can be calculated as:

$$
R_{i} \underline{\%}=\underline{100}\left(N D V I_{W i} / N D V I_{O i}\right)
$$

This woody NDVI percentage of different types of woodlands is shown in figure $\underline{5 \mathrm{~d}}$. In some winters, the values exceed $100 \%$, due to abnormal low NDVI of woodlands caused by an abrupt change, most likely woodland fire (Wu and De Pauw 2010), in which the estimated woody NDVI was higher than the observed one. Based on such abnormality, time-series data can be used for change detection, but it is not the focus of our paper. The calculation results are illustrated in table $\underline{3}$, taking the MODIS NDVI images of 2007 as example. These R values were determined for all pixels of the given savannah woodlands.

Table $\underline{3}$. Woody NDVI percentage in summer and autumn

Figure 5. Seasonal component, trend and baseline of NDVI series, and the ratio between the woody component and the observed NDVI

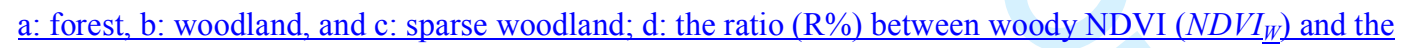
observed NDVI $\left(N D V I_{\underline{O}}\right)$. Note: numbers on horizontal axis represent monthly time steps, with 1: January 2002 and 96: December 2009; 67-68 and 71 indicate respectively the summer (July-August) and autumn (November) of 2007.

\subsection{Application of models}

Application of the models to conduct region- or country-scale woody biomass assessment consists of production of the critical input, the woody NDVI data (2.5.1), and model weighting based on the dominance of vegetation species in each community, and community-scale model application (2.5.2). 


\subsubsection{Producing summer (peak) and autumn (trough) cloud-free woody NDVI images}

Tropical savannahs are frequently covered with clouds in summer and autumn, especially in $\underline{\text { Sudanian and Congolian eco-regions. In order to have higher possibility to get cloud-free NDVI for }}$ each pixel, we used the 8-days interval MOD09Q1 reflectance data (table 1) $\underline{\text { of } 2007 \text { in consideration }}$ of the fact that most of the QuickBird images in Google Earth used for CC sampling were dated 2004-2007. The reflectance data from 01 July to 30 September (12 acquisitions) and from 01 November to 03 December (5 acquisitions) were converted into NDVI. An algorithm was designed to extract the maximum value of each pixel of the 12 summer acquisitions, and the observed peak NDVI (or wet season cloud-free NDVI) -image was thus produced; the same function was applied to the five November NDVI images to extract the autumn_(or dry season cloud-free) NDVI for each pixel.

In the FAO classified sparse woodlands, woodlands, and forests, the decomposed woody NDVI percentage as shown in table $\underline{3}$, was respectively applied to the summer/peak -and autumn/trough cloud-free MODIS NDVI images to produce summer and autumn woody component $\left(N D V I_{W}\right)$ images.

\subsubsection{Vegetation community-based model weighting and application}

As aforementioned, due to the strong variability and mixture of the dominant woody species crossing different savannahs, it is important to take account of- a combination use of the two biomass models (Models 1 and 2). This could be done by adjusting the models to the woody species composition of each vegetation community, or more concretely, vegetation community-level model weighting.

In order to identify the woody species communities in different savannahs, we used the Vegetation Map of Sudan by Harrison and Jackson (1958). To account for the dominance and composition in woody species, a weight ratio between Model 1 (equation (6)), and Model 2 (equation (7)) was estimated for each vegetation community based on the description in the monograph of Harrison and Jackson (1958). The model weights were determined subjectively based on our expert knowledge. Taking the community "Low rainfall woodland savannah, on sand (c) Terminalia-SclerocaryeaAnogeissus-prosopis Savannah Woodland" in the Sahelian eco-region (see table 1) for example, the dominant woody species are Terminalia, Sclerocaryea, Anogeissus, and Proposis which are dominant species in Sudanian eco-region, mixed locally with Acacia senegal. So we gave a weight 0.2 for Model 1 and 0.8 for Model 2. If the Acacia-dominated model (Model 1) were used only, woody biomass would be underestimated. Another example is the community "Special areas of low rainfall woodland savannah (b) Hill Catena East (North of Kurmuk)" in Sudanian eco-region (see table1). This community is geomorphologically a part of the west slope of the Ethiopian Highlands extending to Sudan, dominated with Acacia seyal and Balanites but is at lower elevations mixed with more Anogeissus and Combretum species. To account for this effect a weight 0.6 was given for 
Model 1 and 0.4 for Model 2. The result after weighting should be closer to the reality than a simple application of Model 2.

One point to be noted here is that the Congolian eco-region in the southwest of Sudan (figure 1), the former rainforests, can for practical purpose be considered a part of the Sudanian Savannah, because the rainforests have degraded into woodlands (see table 1) due to burn-and-slash agricultural activities over the past 200-300 years (Harrison and Jackson 1958).

In accordance with the weights given in table 1 , Models 1 and 2, either single or in combination, were applied to both the decomposed summer and autumn woody NDVI images in each vegetation community to produce the aboveground woody biomass maps of both summer and autumn.

\subsection{Evaluation of two biomass maps}

To evaluate whether the two biomass maps of summer and autumn produced in subsection 2.5 are consistent with each other, a differencing procedure was again applied; more concretely, the summer biomass map was subtracted by the autumn one to check the variation and difference between the two maps in space.

Given M (0.232), $\sigma$ (5.542), Min (-49.99), and Max (45.99) of this difference map, it follows that the pixels falling in the extent between $M-\sigma$ and $M+\sigma$ hold an absolute percentage, $84.12 \%$. The positive difference $(\mathrm{M}+\sigma, \mathrm{Max}), 7.98 \%$, implying that the estimated summer biomass density is higher than that of autumn, is mainly distributed in Saharan, and in particular, in Sahelian Savannahs and northern Sudanian Savannah; whereas the negative difference (estimated autumn biomass higher than the summer one), about $7.90 \%$, is found mostly in the Sudanian Savannah. An investigation was conducted firstly in the Sahelian Savannah. If we can briefly consider one tree or big shrub containing 0.5 tons of woody biomass in average, and if the tree number in the 1-ha area is known, the woody biomass can be largely estimated. We used the $249(177+72) \mathrm{CC}$ sampling plots and examined those falling in the Sahelian area, and found that the autumn biomass is closer to the "real" approximation and the summer biomass is overstated. A similar check was undertaken in the Sudanian Savannah supposing that the average tree biomass density is about 2-5 tons per tree depending on the size of tree. It is noted that the woody biomass in some plots is in between the two maps, while in others it is closer to the summer one. Thus the summer map may be slightly better estimated in the Sudanian Savannah. One potential option is to combine the two maps to take the average for the Sudanian Savannah woodlands, and the autumn estimation for Saharan/Sahelian Savannahs.

\section{Results and discussion}

Through the above processing procedure, the results obtained are presented here for discussion. 


\subsection{CC-NDVI model}

Our study found that among the observed vegetation indices, the atmospherically corrected and reflectance-based NDVI shows the best correlation with $\mathrm{CC}\left(\mathrm{R}^{2}=0.91\right)$. This validated CC-NDVI model can predict well CC in woodland savannahs, in particular, in the Saharan and Sahelian

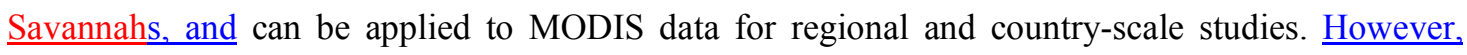
some care has to be taken while deriving CC using this model. As mentioned above, we checked the outliers, the plots where there is significant difference between the measured and predicted CC, and noted that they are all located in the Sudanian eco-region (either in rainforests in the mountains or in the plain where there is green herbaceous vegetation even in dry season). The difference between the predicted and measured $\mathrm{CC}$ in these plots may be caused by (1) the difference in time acquisition between Landsat and QuickBird images, (2) the slope effect in the mountains leading to that NDVI cannot fully reflect the real CC, and (3) the model itself is not suitable for the closed rainforests (normally with CC more than $85-90 \%$ ). With the concern of the third point, a further check was made in the Imatong Mountains (Mts) in south Sudan. Given that the top CC of the closed rainforest is $100 \%$ (theoretically reasonable), we found that our model overestimated CC (more than $100 \%$ ) in about $39 \%$ of the pixels in the closed rainforests in this montane area. Hence, adaption or modification is essential if one wants to apply this model for CC characterization in the closed rainforests.

\subsection{Woody biomass maps}

Using the described multiscale remote sensing methodology ${ }_{2}$ obtained and evaluated woody biomass maps were presented in figure $\underline{6}$ and total biomass $\underline{\text { of forests, woodlands, sparse woodlands, and all }}$

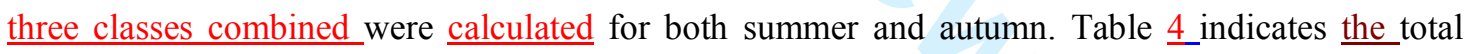
woody biomass estimated in Sudan in 2007 in the range 733-751 million tons. Though some variation found between the two maps, e.g. slight overestimation of the summer map in Sahelian savannah (green in figure 7), and overestimation of the autumn map in Sudanian eco-region (see brown in figure 7), largely speaking, the total woodland biomass is almost the same between summer and autumn with a little difference of $2.4 \%$. Furthermore, the estimates for specific States are also in good agreement with the ground data of woody biomass and the results obtained by other authors. The field-measured values by Helldén and Olsson (1982, 1989), and by Helldén (1987b, 1991), in the Northern Kordofan and Kassala States (Acacia-dominated savannahs with a woody canopy cover range 3-47\% Lare in the range $0.14-18.63$ tons $\mathrm{ha}^{-1}$. The values predicted from our remote_sensing-based approach are in the range 0-21.19 $\underline{\text { tons }_{\text {ha }}{ }^{-1} \text { for Kassala and 0-23.78 tons ha }}{ }^{-1}$ for Northern Kordofan, with a CC range of Acacia trees and shrubs $0-50 \%$. Our results for the | mountain forests (12-161 tons_ha $\left.{ }^{-1}\right)$ also agree well with those of Baccini et al. (2008), who 
conducted a rainforest biomass assessment in Central Africa using MODIS and Lidar data, and estimated for Southern Sudan the woody biomass of forests in the range 11-166 tons ha ${ }^{-1}$.

Table 4 . Estimated summer and autumn woody biomass in Sudan

Figure 6. Woody biomass of Sudan in the summer (left) and autumn (right) of 2007

\subsection{Applicability of the method}

The consistency between the two summer and autumn biomass maps, and the agreement between our results and the ones of other authors, indicate that although we could not conduct field work due to security reasons, the developed methodology can produce reliable woody biomass assessments and can therefore be contemplated for operational use in tropical Africa north of the equator. However, two points are worthy of attention:

Firstly, in our estimation approach the decomposed results of the sampled forests, woodlands, and sparse woodlands were used for a countrywide biomass assessment. Inevitably, for some pixels biomass will be underestimated and for others overestimated due to spatial variability, for example, overestimation in the Saharan/Sahelian eco-region in the summer map. Therefore, the biomass quantity modelled for each pixel should be regarded as a relative value, rather than an absolute indication of stand volume for commercial usage. In next stage, we can try eco-region level or even vegetation community level decomposition to take the spatial variability into consideration to get the estimation as approximate as possible to the reality.

Secondly, the model coupling CC and woody NDVI may lose its sensitivity when CC is below $5 \%$ due to the soil influence or over $75 \%$, especially in the closed rainforests due to overestimation; and hence, the estimation result may be less accurate at the extremes of $\mathrm{CC}$ than in the middle parts (CC $10-60 \%)$.

Figure 7. Difference between the summer and autumn biomass maps

Note: Green colour indicates (1) the estimated summer biomass higher than autumn one and (2) overestimation of summer biomass in comparison with the "real" approximation (see subsection 2.6); and brown implies (1) the obtained autumn biomass is higher than the summer one and (2) a slight overestimation of autumn biomass compared with the "real" approximation. 
As for other tropical savannah in Africa, e.g. Miombo Woodland (south of the equator), the developed methodology may be extendable with some slight adaption in WB-CC model since a lot of woody species (Isoberlinia, Terminalia, Combretum, Burkea Africana, Mopane, etc.) are the same as in Sudanian eco-region. Yet, while disseminating the method to other non-tropical savannahs, more adaption and calibration on the CC-VI and WB-CC models are necessary due to the difference in woody species and endemic environment from our study area. Theoretically, the method should be repeatable if there are land cover map and vegetation community information. Time-series decomposition to derive the woody component is applicable in any savannah.

\section{Conclusions}

This paper describes through a case study in Sudan the development and large-scale operational use of a methodology for woody biomass estimation in tropical savannahs. The biomass calculation method based on the combination of several procedures involving CC-VI_calibration and evaluation, upscaling from high resolution (Landsat) to moderate-resolution (MODIS) data, time-series NDVI decomposition to extract the woody component, biomass model weighting in line with the dominant woody species, and application of models to vegetation communities, is scientifically sound and can provide reliable biomass assessment. The results obtained in Sudan are compatible with available ground truth data and those presented by other authors. This suggests that our methodology and its principles are operational and can be applied in other tropical African countries where woodland | $\underline{\text { savannahs }}$ are dominant for woody biomass assessment in both wet and dry seasons.

Another important outcome of this research is an innovative approach to derive tree canopy cover (CC) by time-series decomposition analysis superimposed on the CC-NDVI model. Applied to a multi-resolution $_{2}$ multi-sensor and time-series dataset, this new technique allows not only to estimate $\mathrm{CC}$ at any time in each observed year, but also to assess the year-round woody biomass if cloud-free NDVI images are available.

In conclusion, the developed methodology offers a promising approach for year-round woody biomass assessments and monitoring in the tropical savannah woodlands and can contribute to lowcost ${ }_{2}$ large-scale assessment and monitoring of carbon balances in savannah woodland ecosystems at local and regional scales in Africa. The future work will be focused on testing the methodology first in Miombo Woodland and then in other non-tropical woodlands for woody biomass assessment.

\section{| Acknowledgements}

Landsat ETM+ and MODIS _ data employed in this research were freely obtained from the USGS and NASA data servers (http://glovis.usgs.gov and https://pdaac.usgs.gov/lpdaac/products/). We thank 


\section{References}

BACCINI, A., LAPORTE, N., GOETZ, S. J., SUN, M. AND DONG, H., 2008, A first map of tropical Africa's above-ground biomass derived from satellite imagery. Environmental Research Letters, 3, pp.1-9.

BASKERVILLE, G. L., 1972, Use of logarithmic regression in the estimation of plant biomass. Canadian Journal of Forest Research, 2, pp.49-53.

BILLE, J.C.(Ed), 1977, Etude de la production primaire nette d'un écosystème sahélien, Travaux et documents de l'ORSTOM, No.65, pp.1-82 (Paris : ORSTOM).

BROWN, S., GILLESPIE, A.J.R. AND LUGO, A. E.,1989, Biomass estimation methods for tropical forests with applications to forest inventory data. Forest Science, 35, pp.881-902.

BROWN, S. AND GASTON, G., 1995, Use of forest inventories and geographic information systems to estimate biomass density of tropical forests: Application to tropical Africa.

Environmental Monitoring and Assessment, 38, pp.157-168.

CHAVEZ, P. S., Jr., 1988, An improved dark-object subtraction technique for atmospheric scattering correction of multispectral data. Remote Sensing of Environment, 24, pp.459-479.

CHAVEZ, P. S., Jr., 1996, Image-based atmospheric correction — revisited and improved. Photogrammetric Engineering and Remote Sensing, 62, pp.1025-1036.

CAMPBELL, B.M.(Ed), 1996, The Miombo in transition: woodlands and welfare in Africa, pp.273 (Bogor: CIFOR).

CLEVELAND, R. B., CLEVELAND, W. S., MCRAE, J. E. AND- TERPENNING, I., 1990, STL: A seasonal trend decomposition procedure based on LOESS. Journal of Optical Statistics, 6, pp.3-73.

| CRIST, E. P. AND CICONE, R. C., 1984a, Application of the tasseled cap concept to simulated Thematic Mapper data. Photogrammetric Engineering and Remote Sensing, 50, pp.343-352.

CRIST, E. P.AND CICONE, R. C., 1984b, A physically-based transformation of Thematic Mapper data - the TM tasseled cap. IEEE Transaction on Geoscience and Remote Sensing, GE22 (3), pp.256-263.

| DOBSON, M.C., ULABY, F.T., LETOAN, T., BEAUDOIN, A., KASISCHKE, E.S., AND CHRISTENSEN, N., 1992, Dependence of radar backscatter on coniferous forest biomass. IEEE Transactions on Geoscience and Remote Sensing, 30, pp.412-415.

DI GREGORIO, A. AND JANSEN, L.J.M., 2000, Land cover classification system (LCCS) (Rome: FAO).

DIXON, R. K., SOLOMON, A. M. BROWN, S., HOUGHTON, R. A., TREXIER, M. C. AND

| WISNIEWSKI, J., 1994, Carbon pools and flux of global forest ecosystems. Science, 263, pp.185190. 
FAO, 1997, Estimating biomass and biomass change of tropical forests: a Primer ${ }_{2}$ Forestry Paper No.134 (Rome: FAO), Available online at: http://www.fao.org/docrep/W4095E/w4095e00.HTM (accessed in Jan 2009).

FAO, 2000, Forest cover mapping and monitoring with NOAA-AVHRR -and other coarse spatial resolution sensors, -Forest Resources Assessment Programme Working Paper 29 (Rome: FAO). Available at: ftp://ftp.fao.org/docrep/fao/007/ae161e/AE161E00.pdf (accessed in Jan 2009).

FAO, 2003, Land Cover Map of Sudan (Rome: FAO). Available online at: http://www.africover.org/africover initiative.htm (accessed in Jan 2009).

FOLEY, J. A., DEFRIES, R., ASNER, G. P., BARFORD, C., BONAN, G., CARPENTER, S. R., CHAPIN, F. S., COE, M. T., DAILY, G. C., GIBBS, H. K., HELKOWSKI, J. H., HOLLOWAY, T., HOWARD, E. A., KUCHARIK, C.J., MONFREDA, C., PATZ, J. A., PRENTICE, I. C.,

| RAMANKUTTY, N. AND SNYDER, P. K., 2005, Global consequences of land use. Science, 309, pp.570-574.

FOODY, G.M., BOYD, D.S. AND CUTLER, M.E.J., 2003, Predictive relations of tropical forest biomass from Landsat TM data and their transferability between regions. Remote Sensing of Environment, 85, pp.463-474.

FRANKLIN, J. AND HIERNAUX, P. H. Y.,1991, Estimating foliage and woody biomass in Sahelian and Sudanian woodlands using a remote sensing model. International Journal of Remote Sensing, 12, pp.1387 - 1404 .

FROST, P., 1996, The ecology of Miombo woodlands. In The Miombo in transition: woodlands and welfare in Africa, B. Campbell (Ed.), pp.11-58 (Bogor: CIFOR).

GITELSON, A.A., KAUFMAN, Y. J., STARK, R. AND RUNDQUIST, D., 2002, Novel algorithms for remote estimation of vegetation fraction. Remote Sensing of Environment, 80, pp.76- 87.

GITELSON, A. A., 2004, Wide dynamic range vegetation index for remote quantification of crop biophysical characteristics. Journal of Plant Physiology, 161, pp.165- 173.

HALL, C. A. S., DETWILER, R. P., BOGDONOFF, P. AND UNDERHILL, S.,1985, Land use change and carbon exchange in the tropics: I. Detailed estimates for Costa Rica, Panama, Peru, and Bolivia. Environment Management, 9, pp.313-333.

HARRISON, M. N. AND JACKSON, J. K.,1958,-Ecological classification of the vegetation of the Sudan. Forests Bulletin No. 2, pp.1-45 (Khartoum: Agricultural Publications Committee).

HEISKANEN, J., 2006, Estimating aboveground tree biomass and leaf area index in a mountain birch forest using ASTER satellite data. International Journal of Remote Sensing, 27, pp.1135-1158.

HELLDÉN, U.AND; OLSSON, K., 1982, The potential of Landsat MSS data for wood resources monitoring - - a case study in arid and semiarid environment in Kordofan, Sudan. Rapporter och Notiser No.52, pp.1- 35 (Lund: Lund University).

HELLDÉN, U., 1987a, An assessment of woody biomass, community forests, land use, and soil erosion in Ethiopia: a feasibility study on the use of remote sensing and GIS-Analysis for planning purposes in developing countries, pp1-75 (Lund: Lund University).

HELLDÉN, U., 1987b, Application of remote sensing data for forest mapping: the Gedaref study. Project: Fuelwood development for energy in Sudan, SUD/033/NET, Report No: FAO-FO-GCP/SUD/033/NET, Accession No: 289885, pp. 1-15 (Lund: Lund University).

HELLDÉN, U., AND OLSSON, L., 1989, Fuelwood assessment of the Kassala province, the Democratic Republic of the Sudan. Final report for the Project: Fuelwood development for energy in Sudan, SUD/033/NET, Report No: FAO-FO-GCP/SUD/033/NET, Accession No: 327615, pp.1- 33 (Lund: Lund University).

HELLDÉN, U., 1991, Woody biomass assessment for resources planning and management, eastern region of the Sudan. Final report for the Project: Fuelwood development for energy in Sudan, 
SUD/033/NET, Report No: FAO-FO--GCP/SUD/033/NET, Accession No: 338129, pp.1-21 (Lund: Lund University)

HIERNAUX, P.AND, LE HOUEROU, H.N., 2006, Les parcours du Sahel__Sécheresse, 17, pp.5171.

HUETE, A.R., 1988, A soil adjusted vegetation index (SAVI). Remote Sensing of Environment, 35, pp.121-136.

HUETE, A. R., LIU, H. Q., BATCHILY, K., AND VAN LEEUWEN, W., 1997, A comparison of vegetation indices global set of TM images for EOS-MODIS. Remote Sensing of Environment, 59, pp.440-451.

IPCC, 2001, The carbon cycle and atmospheric carbon dioxide. In Climate Change 2001: The scientific basis_Chapter 3), IPCC Third Assessment Report - Working Group 1, pp.13-238 (Cambridge: Cambridge University).

IVERSON, L. R., BROWN, S., PRASAD, A., MITASOVA, H., GILLESPIE, A.J. R. and LUGO, A.E. , 1994, Use of GIS for estimating potential and actual forest biomass for continental south and southeast Asia. In Effects of land-use change on atmospheric $\mathrm{CO}_{2}$ concentrations, south and southeast Asia as a case study, V.H. Dale (Ed.), pp.68-116 (New York: Springer-Verlag).

KAUFMAN, Y. J. AND TANRÉ, D.,1992, Atmospherically resistant vegetation index (ARVI) for EOS-MODIS. IEEE Transactions on Geoscience and Remote Sensing, 30, pp.261-270.

LU, D., BATISTELLA, M., AND MORAN, E., 2005, Satellite estimation of aboveground biomass and impacts of forest stand structure. Photogrammetric Engineering \& Remote Sensing, 71, pp.967974.

LU, H., RAUPACH, M. R., MCVICAR, T. R. AND BARRETT, D. J., 2003, Decomposition of vegetation cover into woody and herbaceous components using AVHRR NDVI time series. Remote Sensing of Environment, 86, pp.1-18.

| MALIMBWI, R.E., SOLBERG, B. AND LUOGA, E., 1994, Estimation of biomass and volume in Miombo woodland at Kitulangalo forest reserve, Tanzania. Journal of Tropical Forest Science, 7 , pp.230-242.

OLSSON, K., 1985, Remote sensing for fuelwood resources and land degradation studies in

| Kordofan, the Sudan. PhD Thesis, Department of Physical Geography, Lund University, Lund, Sweden.

ORTHMANN, B., 2005, Vegetation ecology of a woodland-savanna mosaic in central Benin (West Africa): Ecosystem analysis with a focus on the impact of selective logging. $\mathrm{PhD}$ thesis, Universität Rostock, Rostock, Germany.

POPESCU, S.C., WYNNE, R. H. AND NELSON, R. F., 2003, Measuring individual tree crown diameter with lidar and assessing its influence on estimating forest volume and biomass. Canadian Journal of Remote Sensing, 29, pp.564-577.

RAUSTE, Y., 2005, Multi-temporal JERS SAR data in boreal forest biomass mapping. Remote Sensing of Environment, 97, pp.263-275.

RODERICK, M. L., NOBLE, I. R. AND CRIDLAND, S. W., 1999, Estimating woody and herbaceous vegetation cover from time-series satellite observations. Global Ecology and Biogeography, 8, pp.501-508.

ROUSE, J.W., HAAS, R.H. JR., SCHELL, J.A. AND DEERING, D.W., 1973, Monitoring | vegetation systems in the Great Plains with ERTS. In Third ERTS-1 Symposium, NASA SP-351 (1), pp.309- 317.

SAWADOGO, L., SAVADOGO, P., TIVEAU, D., DAYAMBA, S. D., ZIDA, D., NOUVELLET, | Y., ODEN, P. C., AND GUINKO, S.,2010, Allometric prediction of above-ground biomass of 
eleven woody tree species in the Sudanian savanna-woodland of West Africa. Journal of Forestry Research, 21, pp.475-481.

| SUGANUMA, H., ABE, Y., TANIGUCHI, M., TANOUCHI, H., UTSUGI, H., KOJIMA, T.; $\underline{\text { AND }}$ YAMADA, K., 2006, Stand biomass estimation method by canopy coverage for application to | remote sensing in an arid area of Western Australia. Forest É cology and Management, 222, pp.7587.

TUCKER, C. J., 1979, Red and photographic infrared linear combinations for monitoring vegetation. Remote Sensing of Environment, 8, pp.127-150.

UNEP, 2006, Africa environment outlook 2 (Chapter 6): Our environment, our wealth, pp. 1-576 (Nairobi: UNEP). Available online at: http://www.unep.org/DEWA/Africa/AEO2 Launch/ (accessed in Feb. 2012).

VERBESSELT, J., HYNDMAN, R., NEWNHAM G. AND CULVENOR, D., 2010, Detecting trend and seasonal changes in satellite image time series. Remote Sensing of Environment, 114, pp.106115.

WESSA, P., 2008, Decomposition by Loess (v1.0.1), In Free Statistics Software (v1.1.23-r6). Available online at: http://www.wessa.net/ (accessed in Mar 2010).

WHITE, F., 1983, The vegetation of Africa, a descriptive memoir to accompany the NESCO/AETFAT/UNSO Vegetation Map of Africa 1:5 million, pp.1-356 (Paris: UNESCO).

Woomer, P.L., Touré, A., Sall, M., 2004, Carbon stocks in Senegal's Sahel transition zone. Journal of Arid Environments, 59, pp.499-510.

WWF (World Wildlife Fund), 2010, South Saharan steppe and woodland, Sahelian Acacia savanna, East Sudanian savanna and Congolian swamp forests, In: C.J. Cleveland; (Ed.), Encyclopedia of Earth. Available online at: http://www.eoearth.org/ (accessed in Oct 2010),

WU, W., 2003, Application de la géomatique au suivi de la dynamique environnementale en zones arides, $\mathrm{PhD}$ Thesis, Université de Paris 1, Paris, France.

WU, W. AND DE PAUW, E., 2010, Tropical woodland biomass burning and carbon emission: A case study in Sudan. In Optical Society of America (OSA) Congress, Conference of Optical Remote Sensing of the Environment-, June 7-9, 2010, Tucson, AZ (Washington: OSA), Paper No: JTuA30.

ZHENG, D., RADEMACHER, J., CHEN, J., CROW, T., BRESEE, M. AND LE MOINE, J., 2004, Estimating aboveground biomass using Landsat $7 \mathrm{ETM}+$ data across a managed landscape in northern Wisconsin, USA. Remote Sensing of Environment, 93, pp.402 - 411. 
Table 1. Woody vegetation diversity and communities in tropical savannahs taking Sudan for example

\begin{tabular}{|c|c|c|c|}
\hline Eco-regions & Vegetation Communities & Model 1 & Model 2 \\
\hline \multirow{7}{*}{ Saharan } & Desert & 0.00 & 0.00 \\
\hline & Montane vegetation in the state of Red Sea (northeast) & 1.00 & 0.00 \\
\hline & Semi-Desert (e) Acacia glaucophylla - A. etbaica Scrub & 1.00 & 0.00 \\
\hline & Semi-Desert (d) Acacia mellifera - Commiphora Desert Scrub & 1.00 & 0.00 \\
\hline & Semi-Desert (c) Semi - desert grassland on Sand & 1.00 & 0.00 \\
\hline & Semi-Desert (a) Acacia tortilis - Maerua Crassifolia Desert Scrub & 1.00 & 0.00 \\
\hline & Semi-Desert (b) Semi - desert grassland on Clay & 1.00 & 0.00 \\
\hline \multirow{11}{*}{ Sahelian } & $\begin{array}{l}\text { Low rainfall woodland savanna, on sand (b) Combretum } \\
\text { cordofaum-Dalbergia-Albizzia sericephela Savanna Woodland }\end{array}$ & 1.00 & 0.00 \\
\hline & Montane vegetation in Jabal Marra Mountains (west) & 0.60 & 0.40 \\
\hline & $\begin{array}{l}\text { Special areas of low rainfall woodland savanna (d) Raqaba } \\
\text { Repeating Pattern }\end{array}$ & 1.00 & 0.00 \\
\hline & $\begin{array}{l}\text { Low rainfall woodland savanna, on clay (c) Anogeissus-Combretum } \\
\text { hartmannianum Savanna Woodland }\end{array}$ & 0.20 & 0.80 \\
\hline & $\begin{array}{l}\text { Low rainfall woodland savanna, on clay (Acacia mellifera } \\
\text { Thornland) (i) on dark cracking clay, alternating with grass areas }\end{array}$ & 1.00 & 0.00 \\
\hline & $\begin{array}{l}\text { Low rainfall woodland savanna, on sand (a) Acacia senegal } \\
\text { Savanna }\end{array}$ & 1.00 & 0.00 \\
\hline & $\begin{array}{l}\text { Low rainfall woodland savanna, on clay (b) Acacia seyal-Balanites } \\
\text { Savanna, alternating with grass areas }\end{array}$ & 0.90 & 0.10 \\
\hline & $\begin{array}{l}\text { Low rainfall woodland savanna, on sand (c) Terminalia- } \\
\text { Sclerocaryea-Anogeissus-prosopis Savanna Woodland }\end{array}$ & 0.20 & 0.80 \\
\hline & $\begin{array}{l}\text { Special areas of low rainfall woodland savanna (b) Hill Catena in } \\
\text { Darfur (west) }\end{array}$ & 0.80 & 0.20 \\
\hline & $\begin{array}{l}\text { Special areas of low rainfall woodland savanna (c) Baggara } \\
\text { Repeating Pattern }\end{array}$ & 0.90 & 0.10 \\
\hline & $\begin{array}{l}\text { Low rainfall woodland savanna, on clay (Acacia mellifera } \\
\text { Thornland) (ii) on hill soils formed in-situ, associated with } \\
\text { Commiphora africana, Boscia senegalensis }\end{array}$ & 1.00 & 0.00 \\
\hline \multirow{8}{*}{ Sudanian } & $\begin{array}{l}\text { Special areas of low rainfall woodland savanna (b) Hill Catena } \\
\text { Nuba (Center, around Kadugli) }\end{array}$ & 0.70 & 0.30 \\
\hline & $\begin{array}{l}\text { High rainfall woodland savanna, laterite catena (a) Anogeissus- } \\
\text { khaya-Isoberlinia Deciduous woodland }\end{array}$ & 0.00 & 1.00 \\
\hline & Montane vegetation in Imatong and Didinga Mountains (south) & 0.00 & 1.00 \\
\hline & Special areas of low rainfall woodland savanna in Toposa Area & 1.00 & 0.00 \\
\hline & Flood Region & 0.50 & 0.50 \\
\hline & $\begin{array}{l}\text { Special areas of low rainfall woodland savanna (b) Hill Catena } \\
\text { South (east of Juba) }\end{array}$ & 0.20 & 0.80 \\
\hline & $\begin{array}{l}\text { Low rainfall woodland savanna, on clay (b) Acacia seyal-Balanites } \\
\text { Savanna, alternating with grass areas }\end{array}$ & 0.90 & 0.10 \\
\hline & $\begin{array}{l}\text { Special areas of low rainfall woodland savanna (b) Hill Catena East } \\
\text { (North of Kurmuk) }\end{array}$ & 0.60 & 0.40 \\
\hline Congolian & $\begin{array}{l}\text { High rainfall woodland savanna, laterite catena (b) Woodland } \\
\text { recently derived from rainforest }\end{array}$ & 0.00 & 1.00 \\
\hline
\end{tabular}


Table 2. Satellite dataset used in this study

\begin{tabular}{|c|c|c|c|c|c|}
\hline \multicolumn{6}{|c|}{ Landsat ETM+ (30 m) } \\
\hline \multicolumn{3}{|c|}{$16 \underline{\text { Scenes for CC-VI Model Development }}$} & \multicolumn{3}{|c|}{11 Scenes for CC-VI Model Evaluation } \\
\hline Scenes & Acquisition Date & $\begin{array}{c}\text { Total Mean } \\
\text { Haze (in DN) }\end{array}$ & $\underline{\text { Scenes }}$ & $\frac{\text { Acquisition }}{\text { Date }}$ & $\frac{\text { Total Mean }}{\text { Haze (in DN) }}$ \\
\hline $173-50$ & 06 Nov 2000 & 7.27 & $\underline{171-49}$ & 30 Nov 2002 & $\underline{0}$ \\
\hline $173-51$ & 06 Nov 2000 & 7.80 & $\underline{171-50}$ & 30 Nov 2002 & $\underline{3.04}$ \\
\hline $173-52$ & 04 Nov 1999 & 17.17 & $\underline{171-57}$ & 30 Nov 2002 & $\underline{4.16}$ \\
\hline $173-53$ & 04 Nov 1999 & 18.16 & $\underline{172-53}$ & $\underline{05 \text { Nov } 2002}$ & $\underline{12.74}$ \\
\hline $173-57$ & 25 Nov 2001 & 17.46 & $\underline{172-57}$ & 21 Nov 2002 & $\underline{12.88}$ \\
\hline $174-51$ & 27 Nov 1999 & 2.22 & $\underline{173-55}$ & 09 Nov 2001 & $\underline{12.75}$ \\
\hline $175-50$ & 07 Nov 2001 & 0 & $176-52$ & 17 Nov 2002 & $\underline{2.40}$ \\
\hline $175-51$ & 18 Nov 1999 & 0.99 & 176-53 & 17 Nov 2002 & $\underline{5.06}$ \\
\hline $175-54$ & 20 Nov 2000 & 17.56 & $177-49$ & 08 Nov 2002 & $\underline{0}$ \\
\hline $175-55$ & 20 Nov 2000 & 18.34 & $177-50$ & 08 Nov 2002 & $\underline{1.36}$ \\
\hline $176-53$ & 17 Nov 2002 & 10.33 & $\underline{179-52}$ & 06 Nov 2002 & $\underline{5.97}$ \\
\hline $176-54$ & 17 Nov 2002 & 12.81 & & & \\
\hline $178-50$ & 12 Nov 2001 & 0 & & & \\
\hline $178-51$ & 12 Nov 2001 & 1.43 & & & \\
\hline $178-53$ & 07 Nov 1999 & 15.01 & & & \\
\hline $179-51$ & 06 Nov 2002 & 3.66 & & & \\
\hline \multicolumn{6}{|c|}{ Time-series MODIS (250 m) } \\
\hline \multirow{2}{*}{ Frames } & \multicolumn{2}{|l|}{ MOD13Q1 } & \multicolumn{3}{|c|}{$\underline{\text { MOD09Q1 }}$} \\
\hline & \multicolumn{2}{|c|}{ Acquisition $\underline{\text { Period }}$} & \multicolumn{3}{|c|}{$\underline{\text { Acquisition Period }}$} \\
\hline H20V06 & \multirow{6}{*}{\multicolumn{2}{|c|}{01 Jan 2002 to 31 Dec 2009}} & H20V06 & \multirow{6}{*}{\multicolumn{2}{|c|}{01 July 2007 to 03 Dec 2007}} \\
\hline H20V07 & & & H20V07 & & \\
\hline H20V08 & & & $\underline{\mathrm{H} 20 \mathrm{~V} 08}$ & & \\
\hline H21V06 & & & $\underline{\mathrm{H} 21 \mathrm{~V} 06}$ & & \\
\hline H21V07 & & & $\underline{\mathrm{H} 21 \mathrm{~V} 07}$ & & \\
\hline H21V08 & & & $\underline{\mathrm{H} 21 \mathrm{~V} 08}$ & & \\
\hline \multicolumn{6}{|c|}{ QuickBird/GeoEye (0.5-2.5m) } \\
\hline $\begin{array}{l}\text { Available in } \\
\text { Google Earth }\end{array}$ & \multicolumn{2}{|c|}{ Feb 2002 to Dec 2009} & & & \\
\hline
\end{tabular}


Table 4. Estimated summer and autumn woody biomass in Sudan

\begin{tabular}{|c|c|c|c|c|c|c|c|}
\hline \multirow[b]{2}{*}{2007} & \multicolumn{2}{|c|}{ 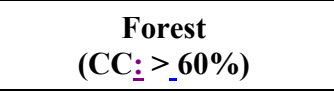 } & \multicolumn{2}{|c|}{$\begin{array}{c}\text { Woodland } \\
\text { (CC: 20-60\%) }\end{array}$} & \multicolumn{2}{|c|}{$\begin{array}{l}\text { Sparse Woodland } \\
\text { (CC: 1-20\%) }\end{array}$} & \multirow[b]{2}{*}{$\begin{array}{r}\text { Total } \\
\text { (tons) }\end{array}$} \\
\hline & $\begin{array}{c}\text { Mean } \\
\text { density } \\
\text { (tons/ha) }\end{array}$ & $\begin{array}{l}\text { Sub-total } \\
\text { (tons) }\end{array}$ & $\begin{array}{c}\text { Mean } \\
\text { density } \\
\text { (tons/ha) }\end{array}$ & $\begin{array}{l}\text { Sub-total } \\
\text { (tons) }\end{array}$ & $\begin{array}{c}\text { Mean } \\
\text { density } \\
\text { (tons/ha) }\end{array}$ & $\begin{array}{l}\text { Sub-total } \\
\text { (tons) }\end{array}$ & \\
\hline Summer & 107.69 & 10604688 & 44.28 & 595649470 & 8.49 & 145053140 & 751307298 \\
\hline Autumn & 98.95 & 9746618 & 44.55 & 599183420 & 7.31 & 124855450 & 733785488 \\
\hline
\end{tabular}




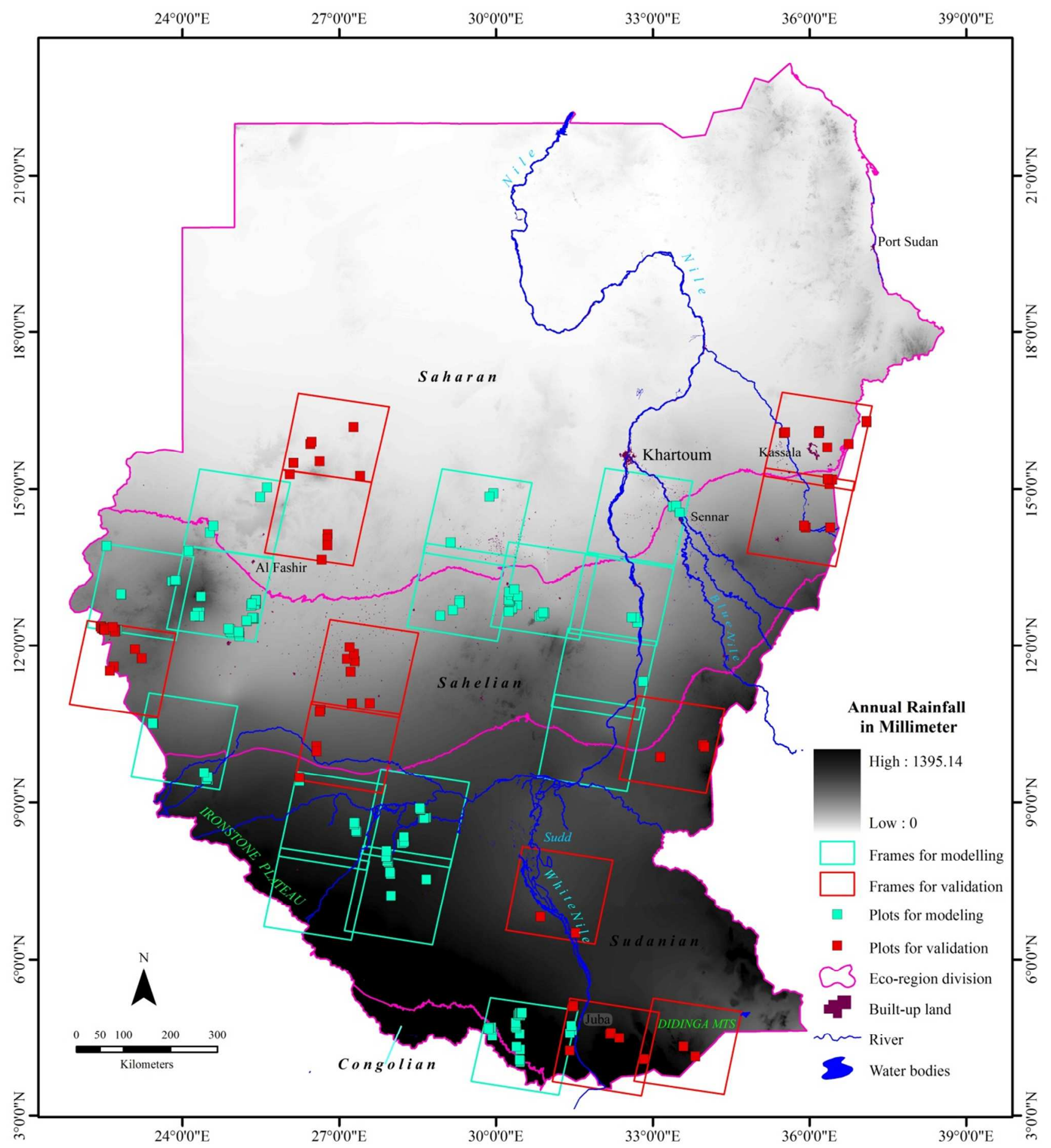

Figure 1. Distribution of CC sampling plots and coverage of Landsat scenes

Note: (1). The division of eco-regions or different savannahs was based on the annual rainfall of the period 1980-1999 according to

WWF (2010); (2) Light blue and red image frames indicate respectively the 16 Landsat ETM+ scenes used for CC-VI model development and 11 scenes for CC-VI model evaluation in this study; (3) two sets of sampling plots: one includes 177 plots (in light blue) for development of CC-VI models and the other contains 72 plots (in red) for CC-VI model evaluation 


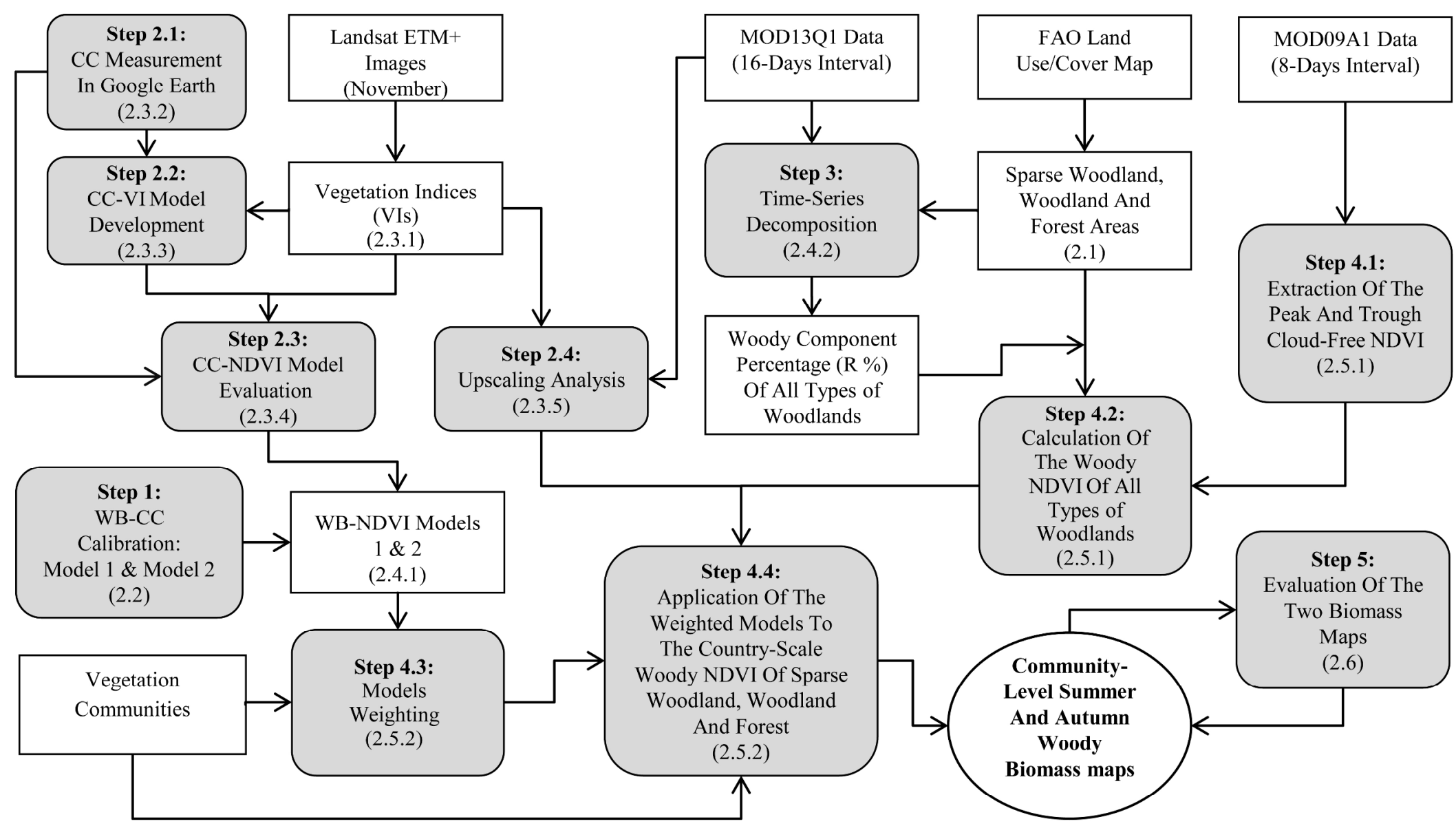

Figure 2. Flow chart of the methodology and procedure adopted in this study

(Note: it is the subsection number in parenthesis) 


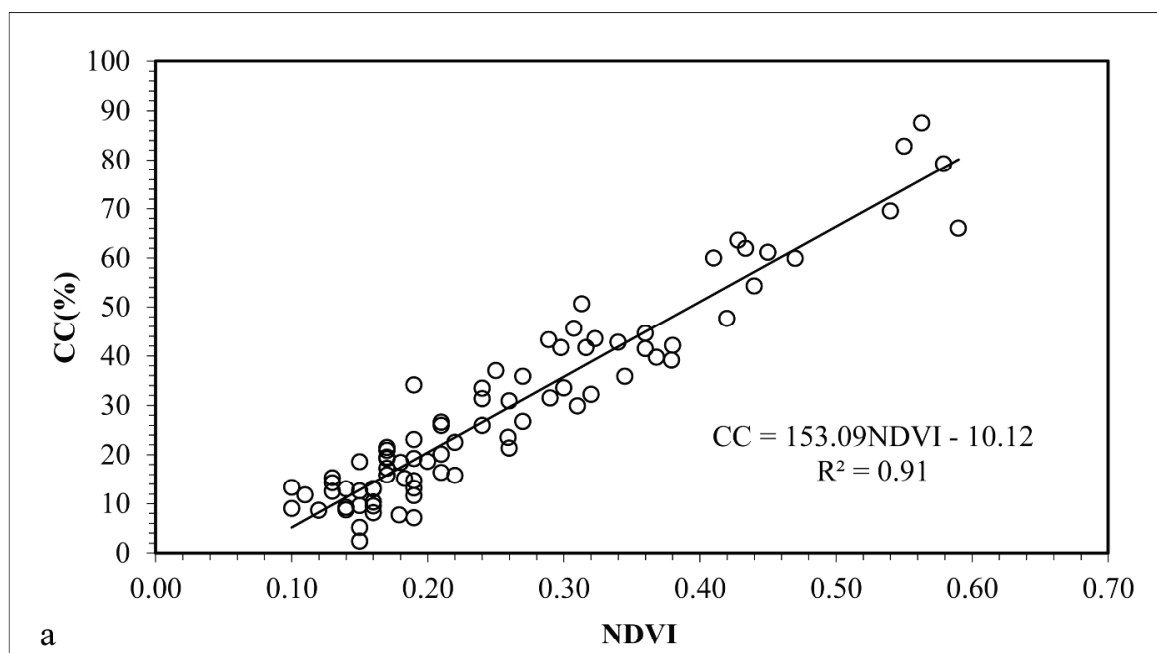

a

$$
\text { NDVI }
$$
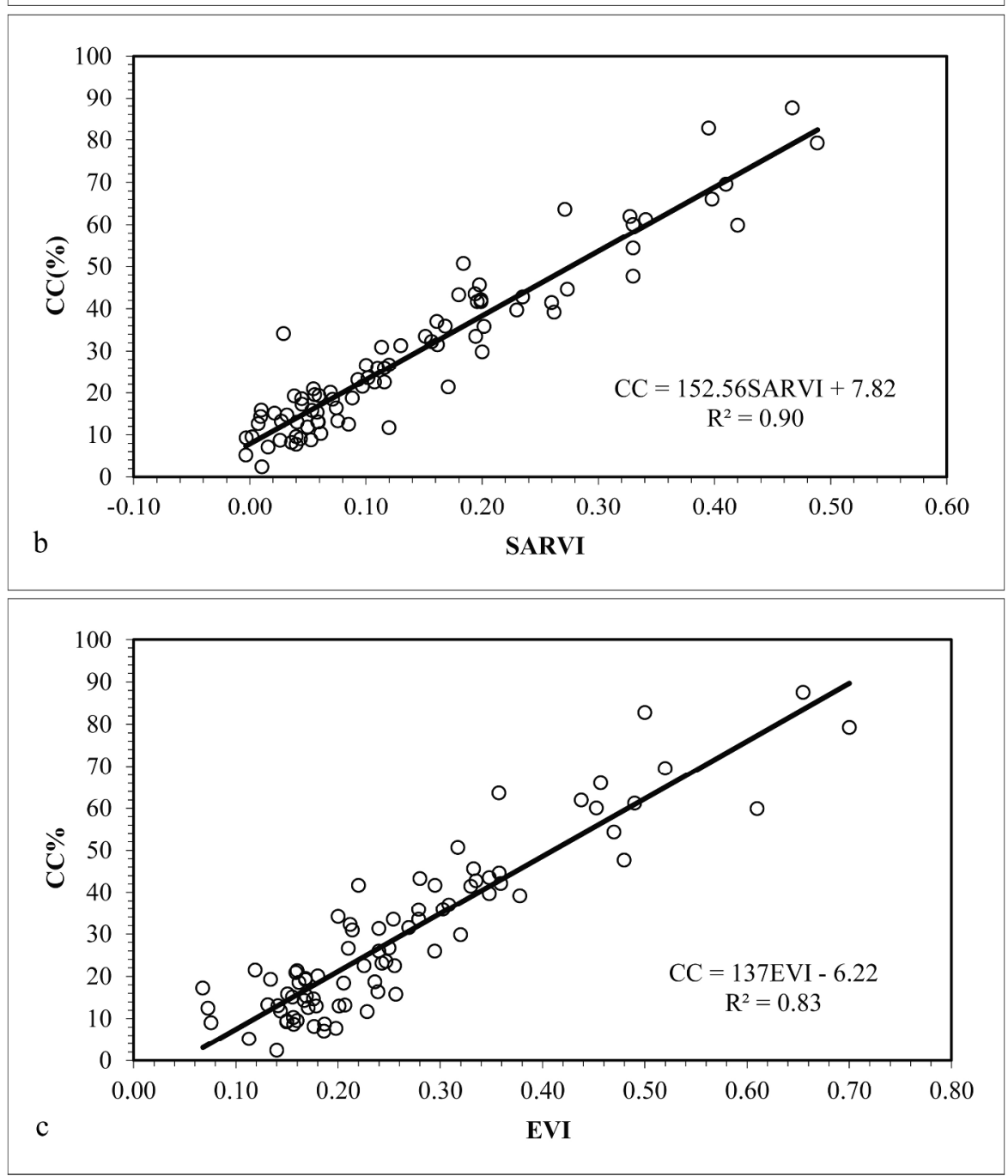

Figure 3. The relationships between the measured CC and VIs 


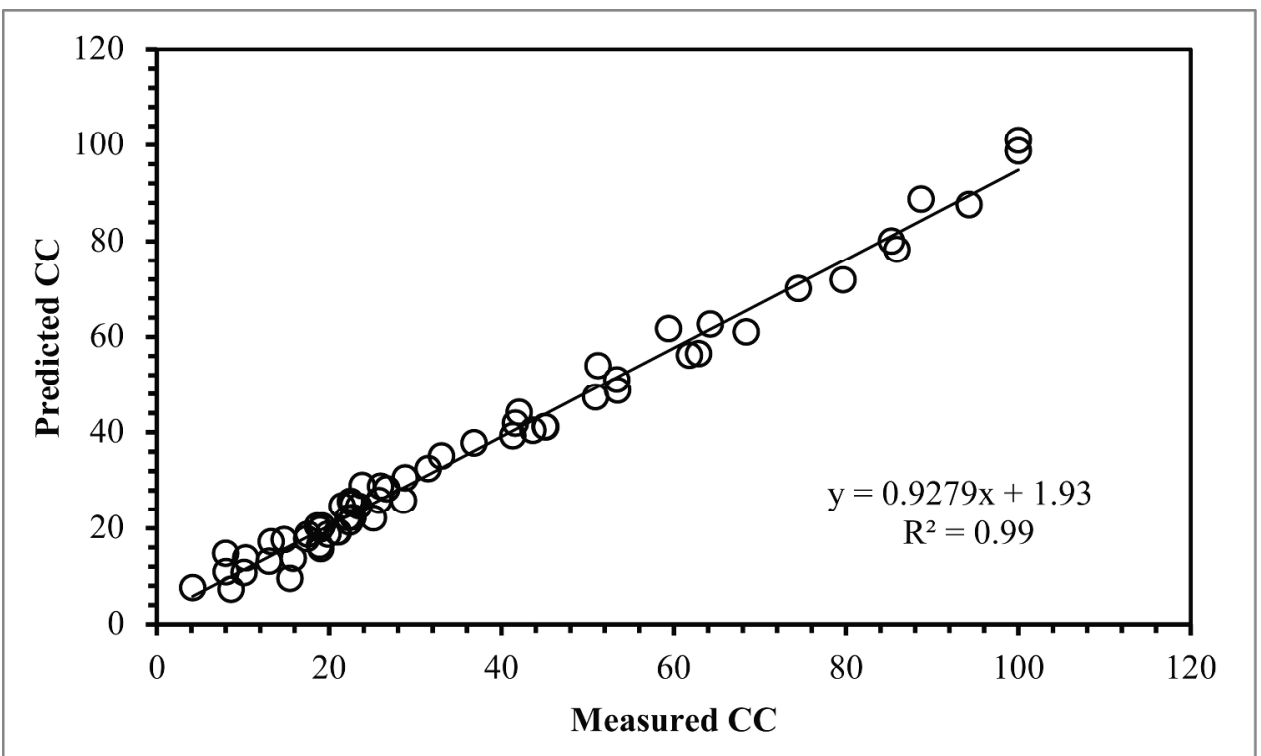

Figure 4. Agreement between the measured and predicted CC 

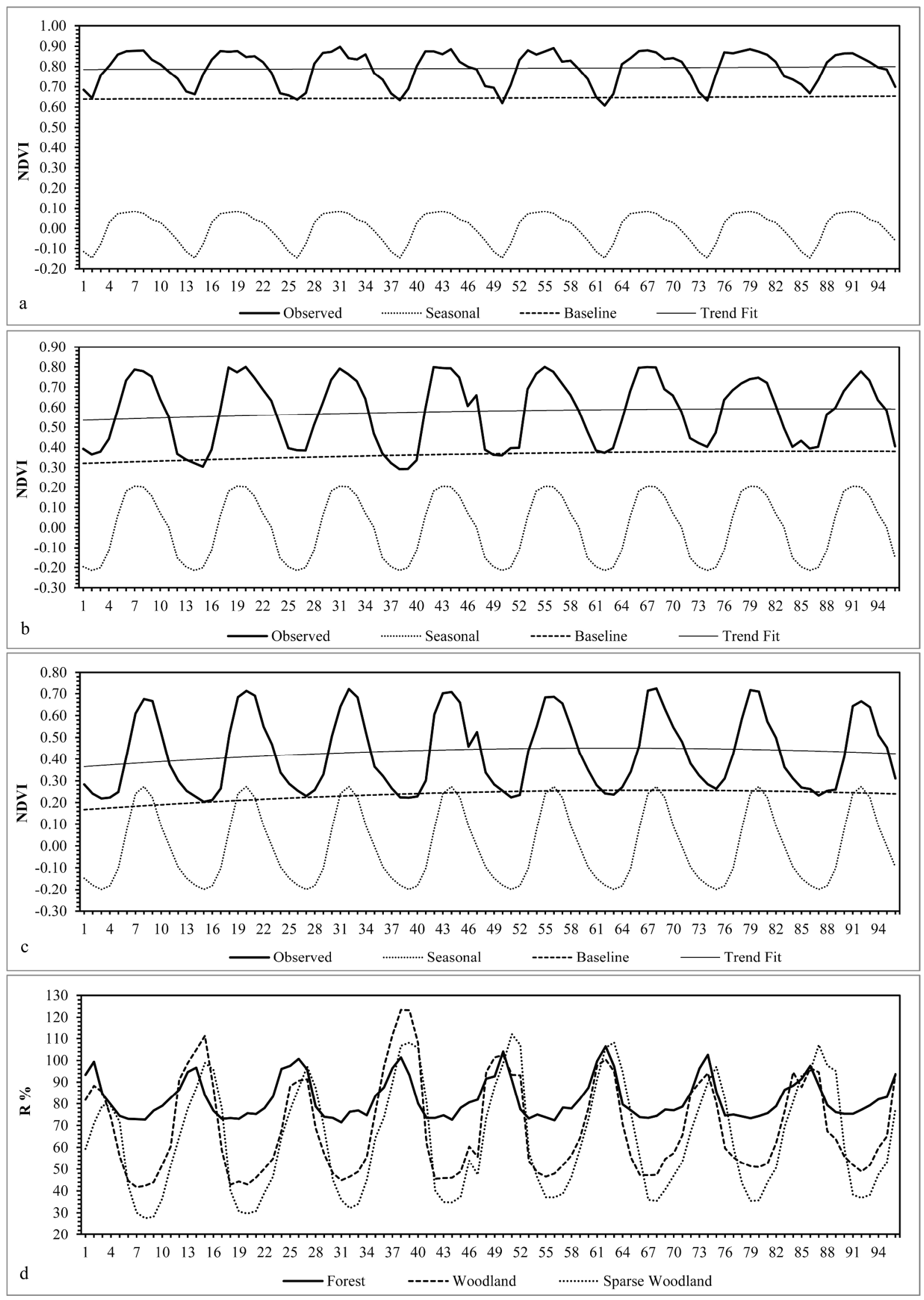

http://mc.manuscriptcentral.com/tres Email: IJRS-Administrator@Dundee.ac.uk 
Figure 5. Seasonal component, trend and baseline of NDVI series, and the ratio between the woody component and the observed NDVI

a: forest, b: woodland, and c: sparse woodland; $\mathrm{d}$ : the ratio (R\%) between woody NDVI $\left(N D V I_{W}\right)$ and the observed NDVI $\left(N D V I_{O}\right)$. Note: numbers on horizontal axis represent monthly time steps, with 1: January 2002 and 96 : December 2009; 67-68 and 71 indicate respectively the summer (July-August) and autumn (November) of 2007. 


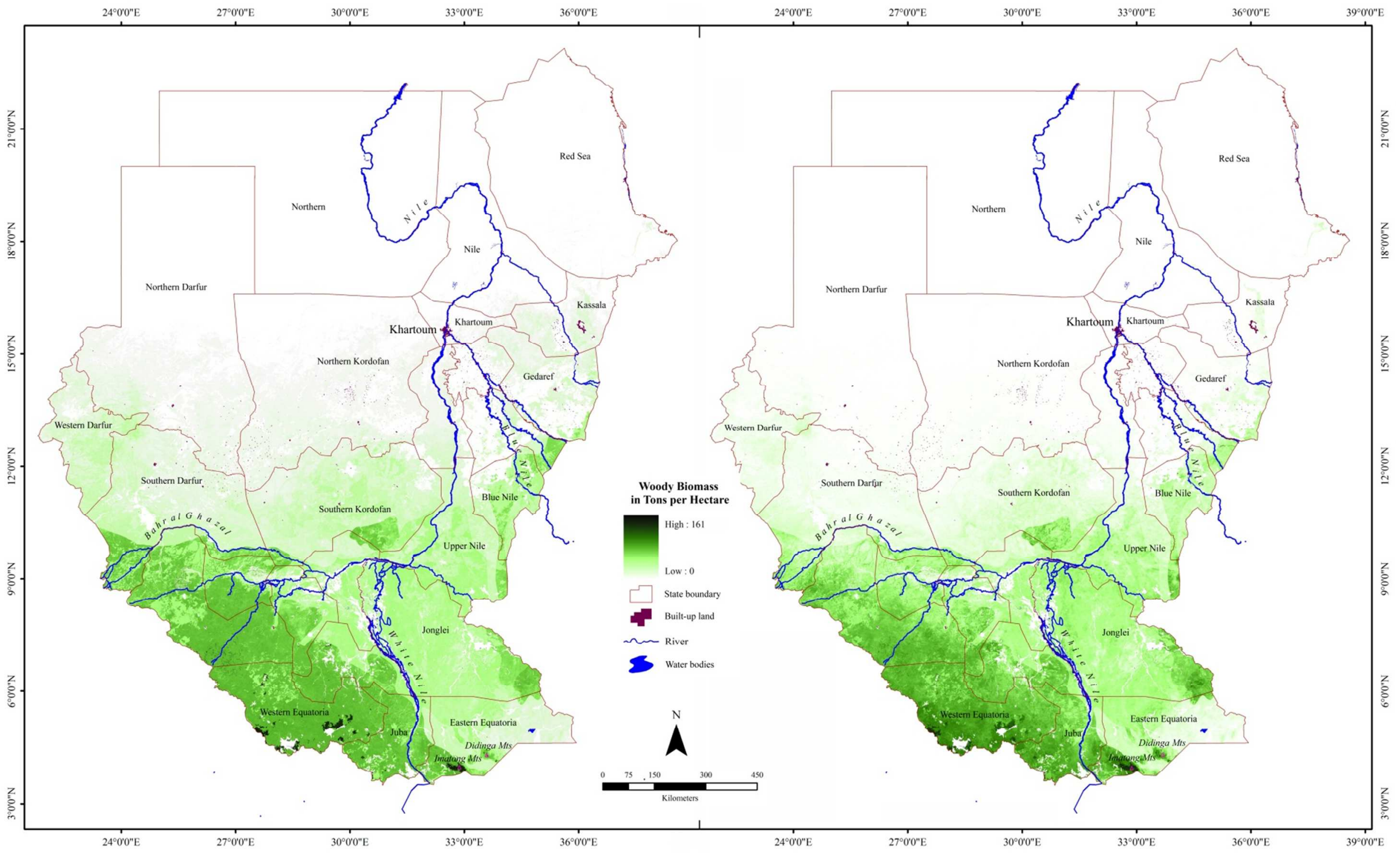

Figure 6. Woody biomass of Sudan in the summer (left) and autumn (right) of 2007

http://mc.manuscriptcentral.com/tres Email: IJRS-Administrator@Dundee.ac.uk 


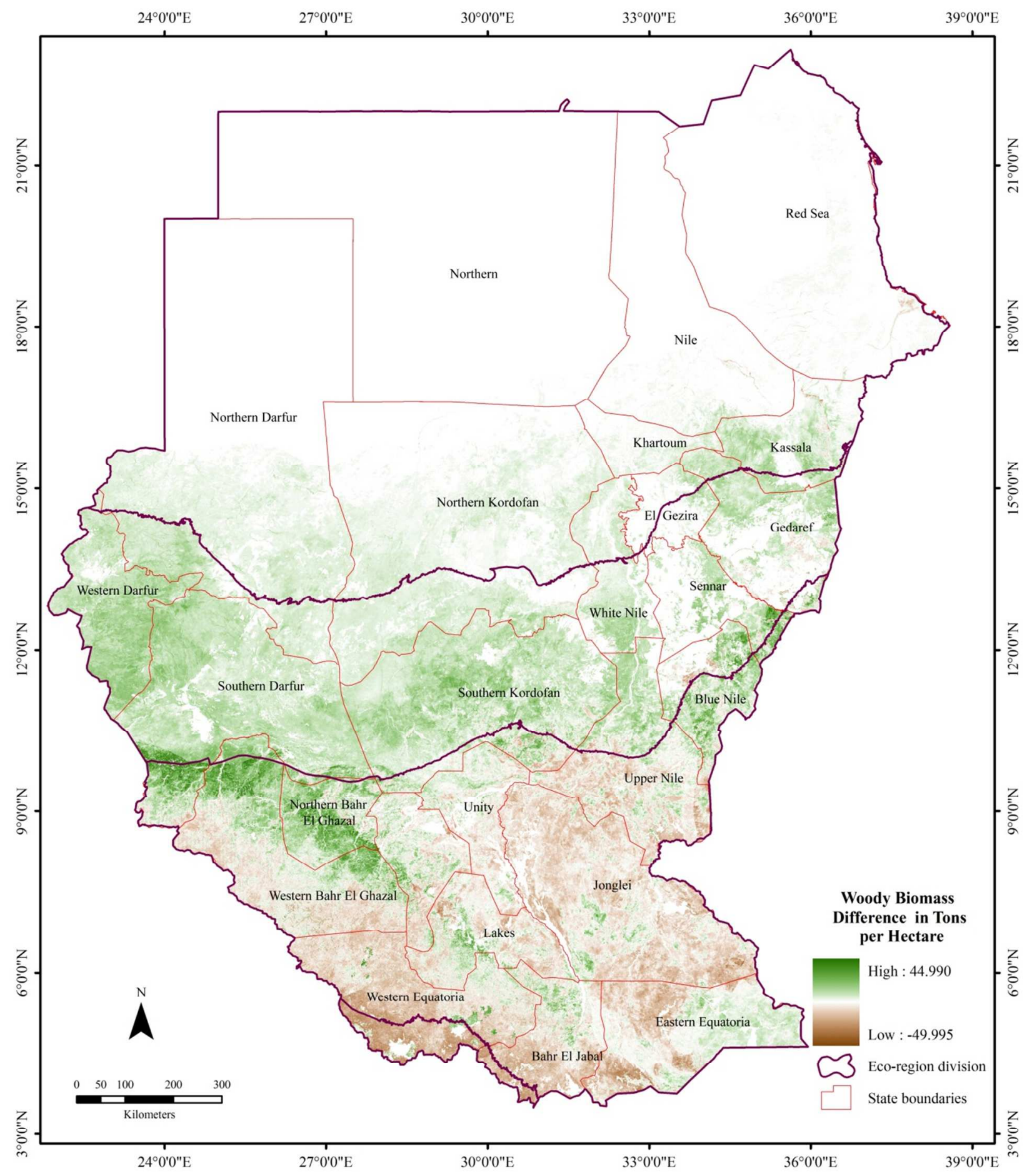

Figure 7. Difference between the summer and autumn biomass maps

Note: Green colour indicates (1) the estimated summer biomass higher than autumn one and (2) overestimation of summer biomass in comparison with the "real" approximation (see subsection 2.6); and brown implies (1) the obtained autumn biomass is higher than the summer one and (2) a slight overestimation of autumn biomass compared with the "real" approximation. 
